Pre-service teachers' evaluation of belief relevant information on a controversial issue in Āotearoa, New Zealand:

Should te reo Māori be compulsory in New Zealand schools?

\title{
By
}

\author{
Una Elizabeth Pania Matthews
}

A thesis submitted to Victoria University of Wellington in fulfilment of the requirements for the degree of

Master of Education

Victoria University of Wellington

2013 


\section{HE MIHI}

Ngā mihi ki te Taitokerau, Te Whare Tapu ō Ngā Puhi te papa kainga o taku Māma:

He mea hanga tōku whare, ko Papatuānuku te paparahi.

Ko nga maunga nga poupou, ko Ranginui e titiro iho nei, te tuanui.

Pūhanga-tohora titiro ki Te Ramaroa e whakakurupaeake ra i te Hauāuru.

Te Ramaroa titiro ki Whīria, te Paiaka o te riri, te kawa o Rāhiri.

Whìria titiro ki Panguru, ki Papata, ki te rākau tū papata ki te tai Hauāuru;

Panguru, Papata titiro ki Maungataniwha.

Maungataniwha titiro ki Tokerau.

Tokerau titiro ki Rākaumangamanga.

Rākaumangamanga titiro ki Manaia, e tu kohatu mai ra i te akau.

Manaia titiro ki Tutamoe.

Tutamoe titiro ki Maunganui.

Maunganui titiro ki Pūhanga-tohora.

Ehara aku maunga i te maunga nekeneke, he maunga tù tonu, tū te Ao tū te Po.

Ko te Whare Tapu o Ngāpuhi tenei, tihei mauri ora.

Ko Hikurangi te maunga

Ko Taumarere te awa

Ko Ngātokimatawhaorua te waka

Ko Matawaia te marae

Ko Nga Puhi te iwi

Ko Ngāti Hine te hapu

Ka mihi hoki ki Tauranga moana, Ngāti Pukenga te papa kainga o taku Pāpa:

E hika tū ake ki runga rā whitiki taua

Hei tama tū. Uea ki te uru kumea ki te tonga.

Hiki nuku, hiki rangi

I arā rā ka ngaru e, ka ngarue

Toia ki te hau marangai, kia whakarongo taku kiri

Te kikini a te rehutai o ngā ngaru whatiwhati

E haruru mai nei

$W \bar{\imath}, w \bar{l}, w \bar{l}$,

$W \bar{a}, w \bar{a}, w \bar{a}$

A! Hā̀ Hā̄!

Horahia ō mata ki a Meremere, Tūahiahi

Hei taki i te ara ki a Tangaroa

He atua hā i te tini ki te pō. E kokoia e ara e!

Ko Kopukairoa te maunga

Ko Waitao te awa

Ko Mataatua te waka

Ko Te Whetu o te Rangi te marae

Ko Ngāti Pukenga te iwi

Ko Ngai Tamarawaho te hapu 


\section{NGĀ MIHI - ACKNOWLEDGEMENTS}

'Seek ye diligently and teach one another words of wisdom; yea, seek ye out of

the best books words of wisdom; seek learning, even by study and also by faith'

$D \& C 88: 11$

Ko te mihi tuatahi ki te Atua, nāna nei ngā mea katoa, nāna i homai, māna e tango, nōreira kororia ki tōna īngoa tapu. Nāna i homai te kaha, me te whakapono i ahau e hīkoi ana i tēnei ara.

Tuarua, ki aku rangatira mātātoa, aku pou, aku whetu i ngā pō pouri, ki a kōrua, Associate Professor Matthew McCrudden kōrua ko Dr Anne Hynds. Nā kōrua i whakapono, nā kōrua i wero mai ki ahau me aku wehi, me aku wanawana. Nā ta kōrua whakapau kaha, me te heke o te werawera ahau i oti tika ai, i eke pānuku ai. Kei runga noa atu kōrua!

Tuatoru, ka tuku mihi maioha atu ki a rātou kua wheturangitia, ko tēnei he mahuetanga o rātou mā. E tangi tonu ana ki a koutou mā kua waiho mai nei i a mātou ki te hīkoi tonu ki roto i tēnei āo hurihuri kia tūtaki anō ai tâtou ki ngā waewae ō te Atua.

Arohanui, Pāpa, Ben Tawa Matthews, e mōhio rawatia nei ahau ko koe tēna e whakakaha ana i ahau i roto i tēnei mahi; Ganama, Eileen Titi Paraha; Ganapa, Tawakehaunga Witehira; taku tungāne Iwingaro Victor Matthews; ki taku whaea a Pepi Walker nāu au i karanga kia ako ai hei kaiako ki Te Whare Wānanga o Waikato, nāu ahau i poipoia, ka tangi tonu.

Ka mihi hoki ki taku whānau o Te Kura Māori, Te Whānau o Akopai aku hoa mahi, ngā mihi maioha hoki ki a koutou. Pania Te Maro, kei reira tonu koe e tautoko ana i ahau me aku wawata whānui. Ki aku hoa kohi raraunga, a Octavia Palmer kōrua kō Katie Omundsen, ka mihi.

Hei whakamutunga māku, ka mihi ki aku hoa me taku whānau, aku tungāne à Tawake, Wake, rātou ko Pene. Ki aku tuakana a Kiri rāua kō Kura, me taku teina a Waireka me ā ratou tamariki maha aroha nui atu ki a koutou katoa. Ki taku whaea, Paremo Matthews, ko au, ko koe, ko tāua tēnei kua eke tahi ai ki tēnei taumata. He whakaaturanga ki te āo o tō aroha, tō whakapono, tō tauira ki ahau. Ko koe taku tino hoa, he aroha e kore e mimiti e te rā.

Firstly, glory to Heavenly Father from which all things are given. He will give and He will take away, all glory to Him. He distilled upon me belief and faith during this great endeavour.

Second, I would acknowledge my supervisors, my leaders, the stars in the night sky, Associate Professor Matthew McCrudden and Dr Anne Hynds. It was you who believed in me, you who challenged me in confronting my fears, and inadequacies. Because you believed in me we have, as a team reached this achievement. You are the best! We made it!

Third, I pay tribute to those who have gone before me, we who are the children of those who have returned to the arms of the Lord. We continue to cry for you, we are still lonely without you here amongst us as we continue on through this life without you. I love you Dad, Ben Tawa Matthews. I know that you are proud of me. Also, to my grandmother; Eileen Titi Paraha and grandfather; Tawakehaunga Witehira. My older brother Iwingaro Victor Matthews and to my mentor and whaea Pepi Walker who encouraged me to attend the University of Waikato for my undergraduate teaching degree.

I must also thank my co-workers, my friends, my confidants at Te Kura Māori, Faculty of Education - Victoria University. You have put many hours and valuable advice towards this result, with me. Pania Te Maro who continued to be a mentor. Also, a big thank you to Octavia Palmer and Katie Omundsen for your hard work. 
Lastly, a mihi to my friends and whānau, my brothers Tawake, Wake and Ben and my sisters Kiri, Kura and Waireka. Thank you for your individual and collective strength.

My whaea Paremo Matthews, this is for you who challenged me on every turn to make sure this is what I wanted to do with my life, time and money. This is a symbol to all of your love and support, your example to me. You are my best friend, teacher, mentor, guidance counsellor and biggest fan.

Arohanui rawa!

With much love and affection! 


\section{TABLE OF CONTENTS}

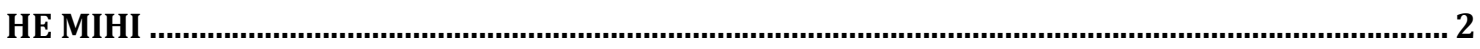

NGĀ MIHI - ACKNOWLEDGEMENTS

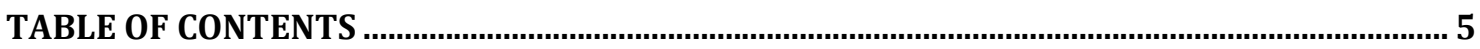

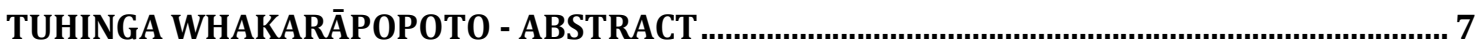

WĀHANGA 1: HEI TIMATANGA - INTRODUCTION CHAPTER

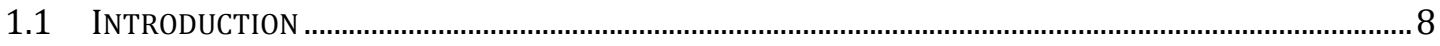

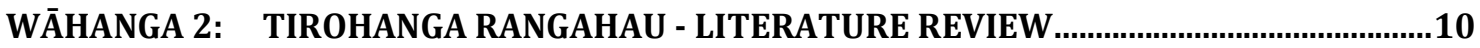

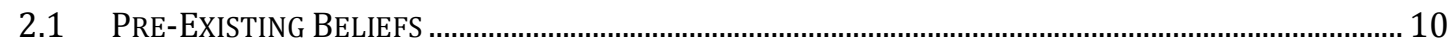

2.1.1 Biased Assimilation and Belief Polarisation.......................................................................... 11

2.2 SuMmary OF STUDIES ON BiaSED ASSIMILATION AND BELIEF POLARISATION................................. 18

2.2.1 Favour belief-compatible arguments ..................................................................................... 19

2.2.2 Negative response to belief-incompatible arguments.............................................................19

2.2.3 Balanced arguments can result in belief-polarisation ........................................................... 19

2.2.4 Balanced text does not lead participants to moderate beliefs..................................................20

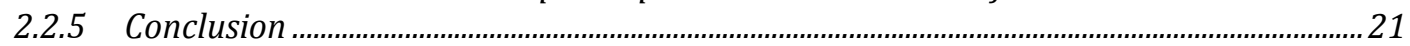

WĀHANGA 3: KAUPAPA RANGAHAU - RESEARCH AIM.....................................................21

WĀHANGA 4: TE WĀHANGA TĀTAURANGA - QUANTITATIVE PHASE _..........................................

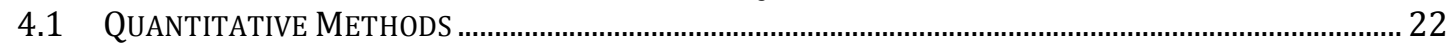

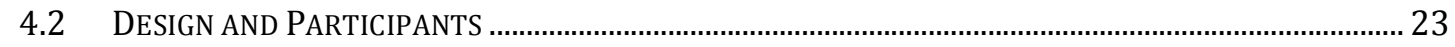

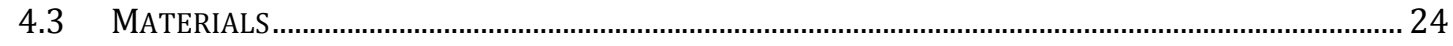





4.3.3. Text

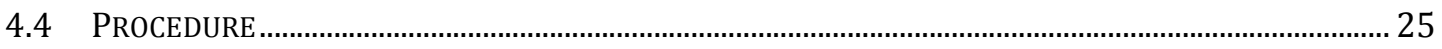

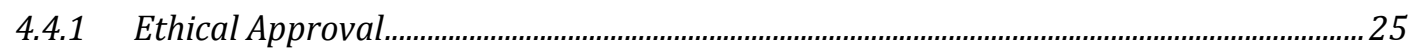

WĀHANGA 5: NGĀ TUKUNGA TATAURANGA - QUANTITATIVE RESULTS............................25

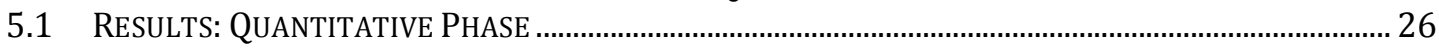

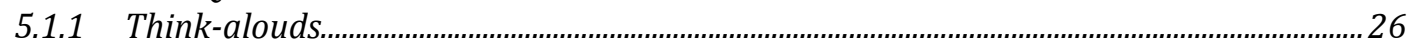

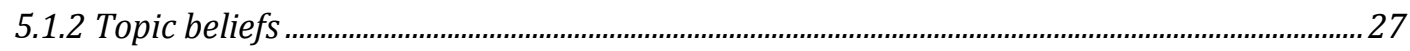

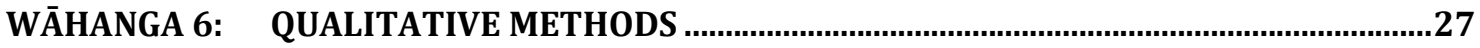

6.1 PARTICIPANTS......................................................................................................................... 27

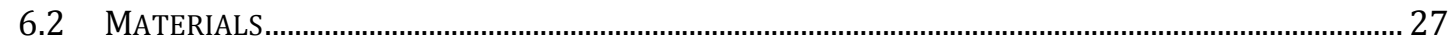

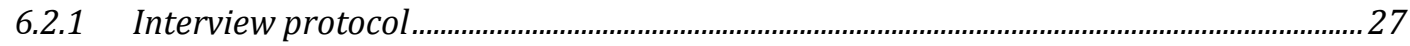

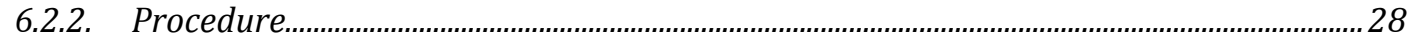

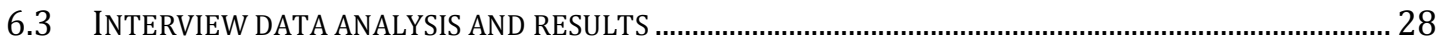

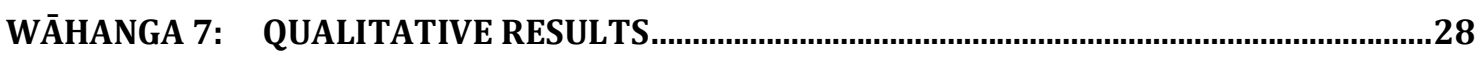

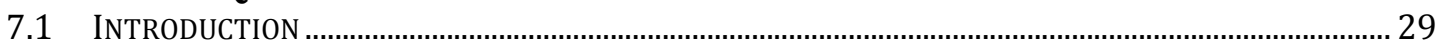

7.2 ANALYSIS OF GROUP 1 - BELIEF MAINTENANCE …………………………………............................ 29

7.2.1 Individual factors: Personal experiences ……........................................................................ 30

7.2.2 Contextual factors: Positive response towards think-aloud task ......................................... 31

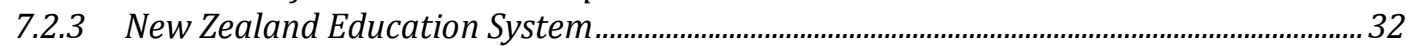

7.3 ANALYSIS OF GROUP 2 - BELIEF-CHANGE ………….................................................................. 33

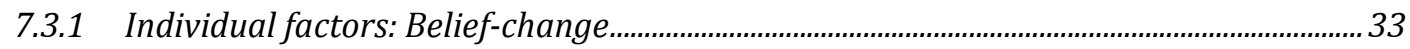

7.3.2 Individual factors: Personal Experience …................................................................................ 34

7.3.3 Emotional response to arguments in the think-aloud text..................................................34

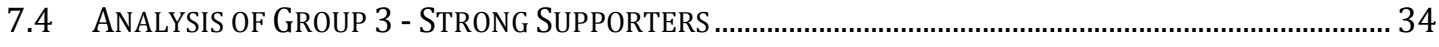



7.4.3 Emotional response to arguments in the text........................................................................... 37

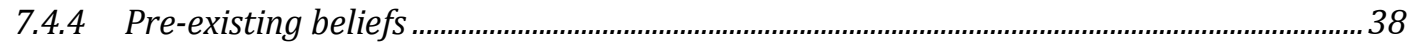




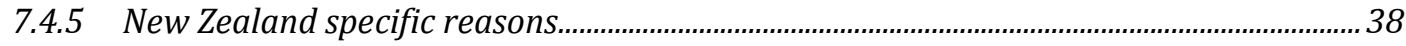

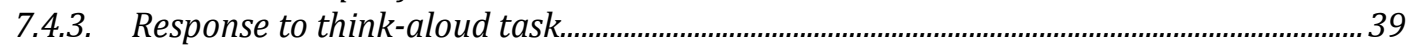

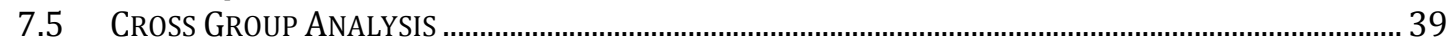

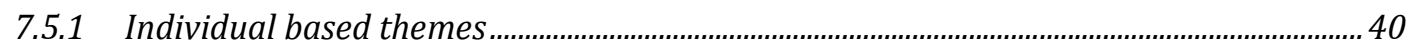

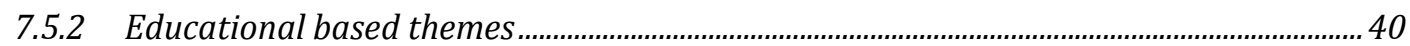

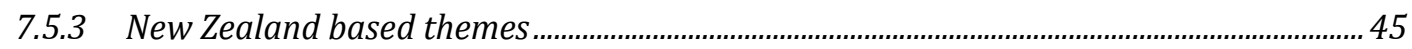

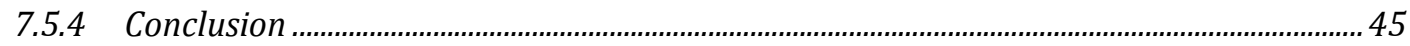

WĀHANGA 8 KAUPAPA KŌRERO - DISCUSSION ......................................................................45

8.1 SUPPORTIVE COMMENTS FOR BELIEF-COMPATIBLE ARGUMENTS.........................................................46

8.2 REFUTATIONAL COMMENTS FOR BELIEF-INCOMPATIBLE ARGUMENTS ................................................ 47

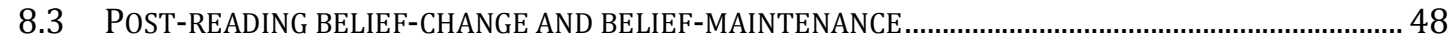

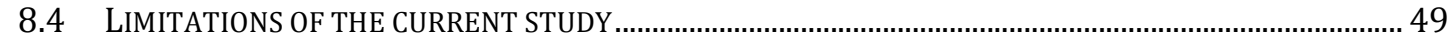

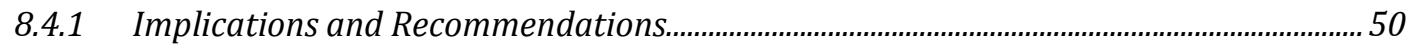

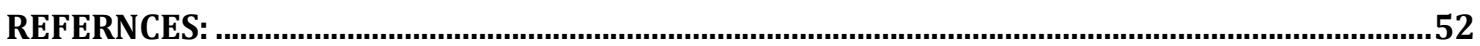

ĀPITIHANGA - APPENDIX A.........................................................................................................56

ĀPITIHANGA - APPENDIX B........................................................................................................57

ĀPITIHANGA - APPENDIX C ........................................................................................................58

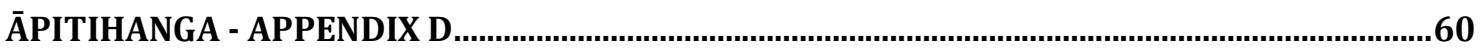



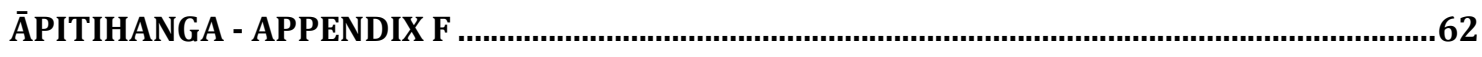

ĀPITIHANGA - APPENDIX G .......................................................................................................64

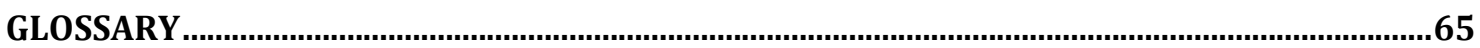




\section{TUHINGA WHAKARĀPOPOTO - ABSTRACT}

The purpose of this mixed methods study was to investigate the influence beliefs have on pre-service teachers' evaluations of belief-relevant arguments and belief change on a controversial issue. In the quantitative phase, pre-service teachers $(n=23)$ at a university in New Zealand completed a topic belief-scale on a controversial issue in Āotearoa/New Zealand (i.e., Should te reo Māori be compulsory in New Zealand schools?). Then they read a text that included arguments for and against compulsory Te reo Māori while they thought-aloud (i.e., verbalized their thoughts as they read). After they read, they completed the topic-belief scale again. The quantitative results showed that participants tended to make refutational comments when they read beliefincompatible arguments, whereas they tended to make supportive comments when the read belief-compatible arguments. Further, their beliefs became stronger after they read. In the qualitative phase, interviews were conducted and analysed to explain why some participants' beliefs became stronger, whereas other participants' beliefs did not change. The interview data revealed individual and contextual factors influenced how participants evaluated the text and were related to their beliefs after they read. These data provide important information about the role of individual experiences in preservice teacher beliefs about a controversial topic on cultural responsiveness. 


\section{WĀHANGA 1: HEI TIMATANGA - INTRODUCTION CHAPTER}

This section will introduce the context of the current research, Āotearoa, New

Zealand. It addresses the disparities in education experienced by Māori as a result of colonisation and the signing of the Treaty of Waitangi in 1840. The subsequent effects colonisation has had on Māori achievement within the New Zealand education system will also be covered in this section.

\subsection{Introduction}

Āotearoa, New Zealand has three official languages: Te Reo Māori, English and New Zealand Sign Language. Te Reo Māori is the native language of the indigenous Māori people of New Zealand. All three languages have special legal status, meaning they can be used within any legal setting in New Zealand, and all are protected under the New Zealand Human Rights Commission. However, English is the most widely used and understood language in New Zealand (Human Rights Commission, 2008-2013). Previous research has indicated that the use of indigenous languages across the world is declining (Hale et al., 1992; Skyhawk, 2012). For instance, since the signing of the Treaty of Waitangi in 1840, a treaty between the independent Māori chiefs of New Zealand and the British Crown, the use of te reo Māori in daily communication has declined tremendously (Waitangi Tribunal, 2010).

The processes of colonisation and cultural assimilation have subjected Māori to systems and practices that are racially and culturally biased against Māori (Ka'ai-Mahuta, 2011; Penetito, 2010), which has had a dramatic effect on Māori language, culture and traditions. For example, Māori are expected to learn, speak and communicate in English, yet there is no expectation that Pākehā are expected to learn and communicate in te reo Māori. This imbalance has led to a devaluing of Māori language, customs and cultural knowledge by both Māori and non-Māori, as evidenced by its dramatic decline in daily use (Ka'ai-Mahuta, 2011; Penetito, 2010; Waitangi Tribunal, 2010). As a result of the potential loss of the Māori language, the New Zealand education curriculum has acknowledged the unique position of te reo Māori in New Zealand and states that all students must "have the opportunity to acquire knowledge of te reo Māori me ōna tīkanga” (Ministry of Education, 2007). However, compulsory te reo Māori for all students in New Zealand schools remains a point of controversy within New Zealand society with both citizens and politicians debating the relevance of the Māori language in New Zealand society (Evans, 2010; Humphreys, 2012; Levy, 2011). 
Today the New Zealand education system is delivered primarily through two methods: English-medium, taught predominantly in English, and Māori-medium, delivered predominantly through te reo Māori in-line with Māori customs and values.

Despite the availability of Māori-medium education to Māori whānau (families), over $90 \%$ of Māori students are enrolled in an English-medium system (Bishop, Berrymann, Cavanagh, \& Teddy, 2009). Also, teachers within the English-medium education system are predominantly Pākehā (NZ European) and middle-class (Ministry of Education, 2013b), many lacking sufficient understanding of te reo Māori, which can contribute to deficit and pathologizing views about the value of Māori language, culture and educational ability (Bishop et. al, 2009, Penetito, 2010). They have viewed Māoritanga (a Māori way of being) as inferior to a New Zealand European language and customs (Bishop \& Berryman, 2007; Bishop et al., 2009; Kane et al., 2005; Penetito, 2010). The compulsory teaching and learning of te reo Māori in New Zealand schools could increase the use of our nation's indigenous language, and by understanding and using te reo Māori, New Zealanders can become more aware of the unique role of Māoritanga in our national identity and not only through the international use of haka in the sporting arena, but also of Māori traditions and practices, and language (Ministry of Education, 2007; Waitangi Tribunal, 2010). However, presently te reo Māori is not compulsory, and many teachers lack an understanding of or have negative views towards te reo Māori, which can contribute to Māori underachievement in schools.

Historically, the New Zealand education system has disproportionally disadvantaged Māori, and is designed to assimilate Māori into a Pākehā world without any expectation for Pākehā to be open to Māori worldview (Penetito, 2010). Ka Hikitia - Accelerating Success 2013-2017 (Ministry of Education, 2013a) is the New Zealand governments' strategy to improve how this system delivers education to ensure Māori enjoy and achieve educational success as Māori. In order to achieve Ka Hikitia objectives, institutions such as teacher training institutions should understand the power pre-existing beliefs have on belief-change. This is especially true with regards to preservice teacher attitudes and beliefs towards te reo Māori ōna tīkanga (Māori language and customs).

Upon graduating from teacher training institutions, New Zealand pre-service teachers become classroom teachers in schools all across New Zealand and the world. Teacher training institutions have a unique opportunity to challenge negative pre-existing beliefs while also providing pre-service teachers with culturally enriching experiences. 
In order for teacher training institutions to prepare pre-service teachers to receive Māori cultural experiences, it is important to understand pre-service teachers' pre-existing beliefs about Māori language and customs. Beliefs are what a person accepts to be true and are not necessarily subjected to scrutiny, and are difficult to alter (Murphy \& Mason, 2006; Tillema, 2000).

It is important to evaluate pre-service teachers' current beliefs and reasoning about te reo Māori in schools (Kunda, 1990; Tippett, 2010). For example, a teacher may oppose compulsory teaching of te reo Māori because he or she believes that it is not as economically beneficial as teaching another language such as Mandarin. Belief change involves the revision or modification of existing beliefs and long held assumptions about what a person accepts as true (Murphy \& Mason, 2006).

\section{WĀHANGA 2: TIROHANGA RANGAHAU - LITERATURE REVIEW}

This section provides a review of key research on the effect pre-existing beliefs have on the evaluation of belief-relevant information and belief change. The literature review introduces and discusses the role of biased-assimilation in the evaluation of beliefrelevant information and its influence on belief change, including belief polarisation. I will discuss these topics in this section. The purpose of this study was to investigate the influence pre-existing beliefs on pre-service teachers' evaluation of belief relevant information and belief change on a controversial issue in Âotearoa New Zealand: the compulsory teaching of te reo Māori in New Zealand schools (Humphreys, 2012).

\subsection{Pre-Existing Beliefs}

The way in which we evaluate controversial issues, such as compulsory te reo Māori in New Zealand schools, is heavily influenced by our pre-existing beliefs. People tend to apply a different standard of evaluation to belief-consistent and beliefinconsistent information. More specifically, individuals tend to apply a lower standard of evaluation to belief-consistent information, yet tend to heavily scrutinize beliefinconsistent information, which in turn tends to leave pre-existing beliefs intact, a process known as biased-assimilation (Edwards \& Smith, 1996; Klaczynski \& Gordon, 1996). Further exposure to belief-consistent and belief-inconsistent information can lead to belief polarisation, which is the strengthening of pre-existing beliefs (Edwards \& Smith, 1996; Lord, Ross, \& Lepper, 1979). 
I reviewed seven empirical articles for the purpose of illustrating the process of biased assimilation and attitude polarisation (Corner, Whitmarsh, \& Xenias, 2012; Edwards \& Smith, 1996; Klaczynski \& Gordon, 1996; Lord et al., 1979; Nir, 2011; Plous, 1991; Taber \& Lodge, 2012). Six articles were conducted in the United States of America (Edwards \& Smith, 1996; Klaczynski \& Gordon, 1996; Lord et al., 1979; Nir, 2011; Plous, 1991; Taber \& Lodge, 2012), and one in Wales, United Kingdom (Corner et al., 2012). I was unable to locate research on biased-assimilation and attitude polarisation within Āotearoa, New Zealand. Two main themes emerged from the studies regarding the effect pre-existing beliefs have on belief change: biased-assimilation and attitude polarisation (Corner et al., 2012; Edwards \& Smith, 1996; Greitemeyer, Fischer, Frey, \& Schulz-Hardt, 2009; Lord et al., 1979; Plous, 1991).

\subsubsection{Biased Assimilation and Belief Polarisation}

Biased-assimilation involves the tendency to evaluate belief-compatible and belief-incompatible information in a biased manner, accepting belief-compatible information quickly while heavily scrutinizing belief-incompatible information (Klaczynski \& Gordon, 1996; Lord et al., 1979). Belief polarisation tends to result from biased assimilation, and results in the strengthening of one's beliefs after exposure to belief-compatible and belief-incompatible information (Corner et al., 2012; Lord et al., 1979; Taber \& Lodge, 2012).

Four empirical studies that investigated biased assimilation are reviewed (Corner et al., 2012; Edwards \& Smith, 1996; Lord et al., 1979; Plous, 1991). One (Lord et al., 1979) is a seminal study that has been significant in this area of research and influenced subsequent studies within this field. Three of the four articles reviewed also provided evidence of attitude polarisation (Corner et al., 2012; Greitemeyer et al., 2009; Lord et al., 1979; Plous, 1991).

The first article Lord et al. (1979) was chosen to review as the researchers investigated university students who hold strong opinions on a complex social issue, and found evidence of biased assimilation and attitude polarisation. They investigated how pre-existing beliefs affect processing belief-compatible and belief-incompatible evidence. In order to find proponents and opponents to capital punishment undergraduate students $(\mathrm{n}=151)$ completed a questionnaire designed to gather pre-existing beliefs and attitudes towards capital punishment. They identified 48 students ( 24 proponents and 24 opponents) with strong beliefs towards the issue. Participants then read two studies on 
the deterrent efficacy of the death penalty: one study provided support for the efficacy of the death penalty, and the second study provided opposing evidence. They were asked to evaluate the persuasiveness and convincingness of both studies, and to judge how well or poorly the respective studies had been conducted.

Lord et al. (1979) have provided insightful evidence into how individuals evaluate belief-compatible and belief-incompatible arguments and identified four main outcomes. First, participants rated the belief-compatible study to be more persuasive. Second, participants rated the belief-compatible study to be more convincing. Third, participants judged the belief-compatible study to be better conducted. Fourth, participants beliefs become stronger or more polarised after they read. These outcomes showed that participants' pre-existing beliefs affected how they evaluated belief relevant information and that pre-existing beliefs are likely to remain intact, and potentially become stronger, after exposure to belief-compatible and belief-incompatible evidence. Unlike Lord et al. (1979), the present study offers an in-depth analysis individuals' interpretations of the text from the participants' perspective.

The second article is Plous (1991), which consisted of three experiments that investigated how beliefs about nuclear technology affect the conclusions people draw from non-catastrophic breakdowns. It was selected for review as it investigated how university students respond to text they strongly agree or strongly disagree with, or have a neutral disposition towards a controversial topic (i.e., nuclear deterrence). In order to determine pre-existing beliefs on nuclear energy and nuclear deterrence in the first experiment students $(\mathrm{n}=215)$ attending a university in America completed a questionnaire designed to gather these pre-existing beliefs. Forty-three students (22 pro-nuclear and 21 anti-nuclear) were identified for holding extreme positions on the issue to continue with the experiment.

Participants then read a three-page binder including excerpts on either nuclear deterrence or nuclear energy that presented a balanced factual overview of a nuclear breakdown and some of the common reactions to these incidents. They were informed that their comprehension of the given text would be tested. Following the reading task, participants completed a multiple-choice quiz, and were asked to write responses to open-ended questions, and indicated whether their opinions had changed on the research topic. Lastly, participants were given structured interview questions that were designed to assess belief change. Plous (1991) found evidence of biased-assimilation and attitude polarisation, showing that both supporters and opponents of nuclear technology 
identified belief-compatible and belief-incompatible evidence within the same text. For example, proponent participants viewed the breakdowns as successful tests of the safeguards, while opponents viewed the breakdowns as evidence of the vulnerability of the system. Some participants' beliefs became stronger after reading the text.

In the second of Plous (1991) experiments, 45 participants were recruited. Twenty-four officers from the Reserve Officers' Training Corps (ROTC) cadets who tended to support nuclear deterrence, and 21 participants from two national peace organisations who tended to oppose nuclear deterrence. The materials were the same as those used in the first study with some additional information about four serious breakdowns that were not well known, and two general questions that asked participants to evaluate their positions on serious break-downs leading to nuclear war, and which aspects of a break-down participants believed could lead to an inadvertent war. This was delivered over three group sessions. Participants who were pro-deterrence viewed the breakdowns as less serious and rated the safeguards higher than participants who were anti-deterrent. These findings closely replicated the results found from the first study: deterrence advocacy increased for those who already supported nuclear deterrence, and declined for those who already opposed deterrence.

In the third experiment from Plous (1991), 63 different university students were identified who had either moderate views or neutral views about nuclear deterrence. The materials used were the same as in the first experiment. Biased-assimilation was less evident amongst participants with lower issue conviction and more evident among participants with higher issue conviction. It is interesting to note the reasoning used by higher issue conviction participants greatly differed to that of lower issue conviction participants. For example, whereas higher issue conviction participants strongly rated themes such as adequacy of safeguards and seriousness of accident, it was not so much for lower issue conviction participants. Thus, they found that polarisation was more likely to occur amongst participants with higher issue conviction than lower issue conviction participants.

Plous (1991) found evidence that technological breakdowns lead to biased assimilation and attitude polarisation even though participants were given the same text. In general, proponents of nuclear deterrence perceived successful safeguards against nuclear breakdown, whereas opponents of nuclear deterrence perceived non-catastrophic nuclear breakdowns as evidence towards a future catastrophe. They also found that after participants read the materials, some proponents lowered their belief in the chances of a 
future nuclear breakdown, while opponents were more confident in a future nuclear breakdown. Plous' (1991) study influenced the current study in that both used balanced text, and interviews. The current study however, included a think-aloud protocol and open-ended interviews to gather an in-depth perspective of participants' cognitive processes.

The third article is Edwards and Smith (1996) adds to the body of research on biased-assimilation (Lord et al., 1979). They hypothesized that people tend to disconfirm or refute belief-incompatible information. This was chosen for review as it clearly demonstrates how participants disconfirm belief-incompatible evidence. To test this hypothesis, Edwards and Smith (1996) conducted two studies. In the first study, 112 undergraduates at a university in America completed a 45-belief statement questionnaire in which they were asked to rate their strength of feeling towards each statement on a four-point scale, and to rate how much knowledge they had about each issue. Of these individuals, 54 were equally knowledgeable about the selected topics and had strong beliefs (either supported or opposed) about the issues of the study. In the first phase of the study, participants evaluated seven of the 45 issues on computers, which recorded their reading times. These issues were selected because an equal amount of participants supported and opposed these particular issues, and were equally knowledgeable. After reading each argument, participants were asked to evaluate the strength of each argument on a seven-point scale. In the second phase of the study, participants completed a thought-listing task that was designed to elicit all thoughts, feelings, and general reactions after they had read each argument. There were three main findings. First, in accordance with the disconfirmation prediction, participants spent more time scrutinizing belief-incompatible arguments than belief-compatible arguments. Second, on the thought-listing task participants generated more thoughts after they read beliefincompatible arguments than after they read belief-compatible arguments. Further, they generated more refutational statements after they read belief-incompatible arguments, whereas they generated more supportive statements after they read belief-compatible arguments. Finally, belief-incompatible arguments were judged as weaker than beliefcompatible arguments.

In the second study in Edwards and Smith (1996), the researchers focused on participant reactions to a single argument (anti-death penalty). The first objective was to control the amount of knowledge participants had about the topic, and to measure emotional conviction. The second objective of the study was to explore the thought- 
listing task and the tendency of participants to generate more thoughts while evaluating belief-incompatible arguments. The researchers asked 212 undergraduates at a university in America to complete a 14-question survey regarding pre-existing attitudes and beliefs towards capital punishment. Eighty-five participants that were strong proponents or opponents of the death penalty and were also rated as neither novices nor experts regarding the death penalty were invited to participate further in the study. Unlike the first study, reading times were not assessed; all tasks were given in packets with written responses. Consistent with their first study, they found that participants rated beliefcompatible arguments as stronger than belief-incompatible arguments. They also found the level of emotional investment in the argument affected the degree of disconfirmation bias; people with greater emotional investment showed a greater degree of disconfirmation. The researchers concluded that people are generally unable to judge an argument independently of their beliefs. Edwards and Smith (1996) found that participants tended to subject belief-incompatible evidence to a deeper level of scrutiny, as evidenced by differences in reading times and responses to the thought-listing task. The present study also aimed to investigate how individual evaluate belief-relevant information, but with the use of a think-aloud task.

The fourth article reviewed, Corner et al. (2012), investigated whether participants experienced biased assimilation and attitude polarisation when reading arguments regarding climate change. This article was reviewed because it investigated biased assimilation and attitude polarisation in a context "representing the first attempt to evaluate individual level attitude polarisation towards climate change" (Corner et al., 2012) such as the present study on compulsory te reo Māori in New Zealand schools. Undergraduates $(\mathrm{n}=173)$ at a university in Wales, United Kingdom participated in this study. Participants were randomly assigned to one of two experimental conditions. In the first condition, participants read two newspaper editorials that made opposing claims about the reality and serious nature of climate change. In the second condition, participants read other two newspaper editorials that made opposing claims about climate change, but they were designed to create political and moral uncertainty about climate change and were from two popular newspapers (Irish Times and Scotsman). Some factors had been previously identified as important elements of skepticism about climate change (age, gender, demographics, political affiliation, and membership in any environmental organisations). Therefore in a computer lab on-campus, participants first completed a demographic survey, then rated personal attitudes towards climate change 
and the environment in general. Second, participants rated 17 statements that identified pre-existing scepticism towards climate change. Third, they read the two opposing newspaper editorials and indicated on a 5-point likert-type scale the persuasiveness and reliability each argument. Lastly, the participants repeated the 17 statements rating task.

They found that participants who were more skeptical about climate change evaluated the newspaper editorials in a distinctly different way to those who were less skeptical about climate change. The less-skeptical participants rated the pro-climate change arguments in the Irish Times as more convincing than the opposing editorial in the Scotsman. Conversely, the more-skeptical participants rated the Scotsman editorial as more convincing than the Irish times. Participants had shown a bias toward beliefincompatible arguments and assimilate these into pre-existing beliefs. The results showed that people experience biased-assimilation after reading opposing arguments regarding climate change. It also highlighted that attitude polarisation does not always follow result from biased assimilation (Corner et al., 2012). This study was conducted in a computer lab, without interviews or opportunity for participants to further elaborate their reasoning.

The four articles reviewed focused on the effects that pre-existing beliefs have on the evaluation of belief-compatible and belief-incompatible information. Often preexisting beliefs influence the extent to which new evidence is accepted, ignored or assimilated to maintain the integrity of initial beliefs (Chinn \& Brewer, 1998; Edwards \& Smith, 1996; Lord et al., 1979). In order for initial teacher training providers to provide enriching and appropriately challenging experiences to pre-service teachers that encourage cultural responsiveness, it is important to understand the effects pre-existing beliefs can have on students' evaluation of belief relevant information.

The fifth article Klaczynski and Gordon (1996), investigated how adolescents evaluated research evidence that conveyed findings that were and were not consistent with their beliefs. This was chosen for review as it demonstrates how adolescents evaluate belief-relevant evidence. Fifty adolescent volunteers ( 27 male, 23 female) from a summer camp in America participated in the study that assessed their reasoning about belief-compatible and belief-incompatible evidence. Participants indicated their religious affiliations, which were then used to tailor problem-solving packets for each participant. Four days later, in the second session participants were given problem-solving packs that consisted of nine research findings that were designed to assess evaluation skills: three were belief-consistent, three were belief-inconsistent, and three were belief-neutral 
evidence. Similar to previous research on biased-assimilation, Klaczynski and Gordon (1996) found belief-compatible arguments were judged as stronger than beliefincompatible arguments and participants found more flaws in the belief-incompatible scenarios. Participants were informed that if their justifications were not well thought, they would be required to further report to an adult, therefore providing motivation for participants to critique in-depth their beliefs. This strategy was not utilised in the present study as it places a negative consequence for what a third party deems insufficient reasoning.

In the sixth article reviewed, Taber and Lodge (2012) used two experiments investigate biased assimilation and attitude polarisation on politically charged issues. This was selected for review for two reasons, the first being that it further investigates biased assimilation and attitude polarisation. Secondly, much like the present study they also use controversial and politically charged issue in which to study. About 170 participants were recruited from a university in America. To begin, they were asked to indicate their positions on battery of items that consisted of politically charged issues, including affirmative action and gun control. Then participants were instructed to process the information about various issues in an even-handed manner. Participants read and responded to 16 policy arguments, which included the source of the argument. Similar to Edwards and Smith (1996), this task was timed in order to evaluate how much time participants devoted to belief-consistent and belief-inconsistent arguments. The same battery test was administered as a post-test. Three main findings emerged from Taber and Lodge (2012) study. First, they found that participants experience a confirmation bias even when presented with both supporting and opposing evidence. Confirmation bias is defined as actively seeking for confirmatory evidence (Taber \& Lodge, 2012). Second, they found that experiencing confirmation bias and disconfirmation bias both lead to attitude polarisation. Third, they found that participants would process belief-compatible arguments faster than belief-incompatible arguments. They found that participants were likely to quickly assimilate belief-compatible arguments into pre-existing beliefs, and scrutinize longer belief-incompatible arguments. Similar to Corner et al. (2012) this study was carried out without further interaction with the researchers.

The final article reviewed, Nir (2011) researched motivated reasoning and perceptions of politically charged issues. It was hypothesized that type (accuracy or belief-confirming) and strength of motivational goals would influence participants' 
beliefs. This study was selected for review because it investigated the reasoning participants used to maintain their pre-existing beliefs and how motivation can affect this reasoning. Nir (2011) used a random sample of 1,684 American citizens over a period of one year, who were registered with Knowledge Network, Inc. (a network of tens of thousands who receive free WebTV and service in exchange for completing a range of online surveys from time to time). First, participants completed a self-rated, 10-sentence motivated-reasoning typology task (e.g. I form opinions about everything; I really enjoy a task that involves coming up with new solutions to problems). The answers to this task then placed them into one of four motivated-reasoning groups: apathetic, partisan reasoned, classical rationalist, and intuitive scientist. They were then asked to indicate how likeable the democratic and republican parties are, and to list reasons why they liked or disliked these parties, and why they thought others would like or dislike these parties. Participants were involved in a discussion forum once a month before and after a moderated online discussion. There were approximately 60 groups of 10-15 participants. Results show two major outcomes. First, participants are motivated to maintain and bias pre-existing beliefs even after controlling influential variables (partisan strength, demographics, news exposure, political knowledge and interest). Second, participants are more likely to reason about opposing positions when accuracy was prioritised.

Because of the scope of this research they were unable to meet face-to-face, however their online-discussions did allow participants to justify and delve into their reasoning. This was completely online and over a longer period of time that the present research had time to conduct.

\subsection{Summary of Studies on Biased Assimilation and Belief Polarisation}

This section provides a summary of the above studies to provide a background for the present study. Previous research has been crucial to developing an understanding of the cognitive processes participants experience while reading belief-compatible and belief-incompatible arguments. Capital punishment (Lord et al., 1979), nuclear energy and nuclear deterrence (Plous, 1991), climate change (Corner et al., 2012), Edwards and Smith (1996) investigated seven salient issues (e.g., death penalty, gun control) are only some of the issues where biased assimilation and belief-polarisation have been investigated. This section will compare and contrast these findings.

Four main findings emerged from these studies. First, participants are likely to accept and favour belief-compatible arguments. Second, participants respond negatively 
towards belief-incompatible arguments. Third, reading both argument supportive and opposing arguments can result in a polarisation of beliefs. And finally, reading balanced text does not automatically lead participants to moderate existing beliefs. All of these studies provided evidence that people process belief-compatible and belief-incompatible information differently.

\subsubsection{Favour belief-compatible arguments}

Edwards and Smith (1996); Lord et al. (1979); Plous (1991) revealed evidence that participants are likely to quickly favour and accept belief-compatible arguments. All of these articles demonstrated that participants were motivated to defend pre-existing beliefs. When presented with belief-compatible arguments, participants quickly accept this evidence because it overlaps with their pre-existing beliefs (Edwards \& Smith, 1996; Lord et al., 1979). This can lead to attitude polarisation (Klaczynski \& Gordon, 1996; Kunda, 1990; Nir, 2011; Taber \& Lodge, 2012).

\subsubsection{Negative response to belief-incompatible arguments}

Chinn and Brewer (1998); Corner et al. (2012); Edwards and Smith (1996); Lord et al. (1979); Nir (2011) highlight that when presented with belief-incompatible arguments participants are likely to do one or more of the following: judge beliefincompatible arguments as weaker than belief-compatible arguments, scrutinize beliefincompatible arguments longer, modify and assimilate these arguments into pre-existing beliefs, and generate more opposing statements. This leaves pre-existing beliefs intact and may lead participants to experience biased assimilation. Being confronted with belief-incompatible arguments triggers cognitive dissonance. Cognitive dissonance is the minds struggle to process new belief-incompatible evidence, however this process will result in participants' tending to bias, alter and assimilate new evidence inasmuch as it leaves pre-existing beliefs intact (Corner et al., 2012; Edwards \& Smith, 1996; Kunda, 1990; Lord et al., 1979; McFalls \& Cobb-Roberts, 2001; Nir, 2011; Plous, 1991).

\subsubsection{Balanced arguments can result in belief-polarisation}

Four of the articles reviewed presented evidence of belief polarisation following evidence of biased assimilation when processing belief-incompatible evidence (Corner et al., 2012; Lord et al., 1979; Plous, 1991; Taber \& Lodge, 2012). In previous research, biased-assimilation was commonly seen as a barrier to the revision of initial individual and group judgments that form participants' beliefs. 
In these four studies, when providing students with text that included both beliefcompatible and belief-incompatible, this was not taken as an opportunity to moderate pre-existing beliefs; rather these beliefs became more polarized (Corner et al., 2012; Lord et al., 1979; Plous, 1991; Taber \& Lodge, 2012).

Corner et al. (2012) added that biased assimilation and attitude polarisation are independent constructs, in that polarisation did not automatically follow biased assimilation. Biased assimilation may result in attitude polarisation, however there are examples provided here where biased assimilation was identified without participants experiencing polarisation of beliefs.

These studies seem to portray biased-assimilation and attitude polarisation in a negative light, as if to experience biased-assimilation and attitude polarisation can lead to ignorance and knowledge deficit. However, this may not always be the case. It is possible that individuals have previously considered an issue and have identified weaknesses in belief-incompatible arguments and do not perceive a need to modify their beliefs after having rejected those arguments on the basis of sound reasoning. For instance, if pre-service teachers support te reo Māori in New Zealand schools, then biased assimilation and belief polarisation can be a positive vehicle for social and restorative justice.

\subsubsection{Balanced text does not lead participants to moderate beliefs}

Previous research has found that reading belief-compatible and beliefincompatible texts can increase polarisation (Edwards \& Smith, 1996; Lord et al., 1979). Lord et al. (1979); Plous (1991) both present evidence of increased polarisation after participants read belief-compatible and belief-incompatible arguments, rather than using the mixed evidence to moderate existing beliefs. (i.e. proponents more in favour of capital punishment, opponents less in favour of capital punishment).

Klaczynski and Gordon (1996); Plous (1991); Taber and Lodge (2012) show that although participants do not moderate their pre-existing beliefs while reading beliefcompatible and belief-incompatible arguments, this is likely to occur when argument comprehension will be tested. For example, the participants of Taber and Lodge (2012) study were informed that if their evaluations of the arguments were poorly written, they would meet one-on-one with an interviewer to further justify their position. This encouraged participants to view the argument objectively, without personal bias. 


\subsubsection{Conclusion}

None of the articles reviewed utilised the think-aloud strategy in order to gather online processing of participants moment-to-moment reasoning of belief-compatible and belief-incompatible evidence.

The previously reviewed literature focused primarily on what happens to preexisting beliefs when people encounter both belief-compatible and belief-incompatible arguments. However, these studies have not investigated the reasoning participants use in order to understand controversial social issues, such as compulsory te reo Māori in New Zealand schools. This is especially important to understand in Āotearoa, New Zealand within initial teacher training programs. Understanding pre-service teacher reasoning and motivation will enable teacher training institutions to better provide appropriate experiences to challenge unproductive bias towards te reo Māori within the English-medium education system.

\section{WĀHANGA 3: KAUPAPA RANGAHAU - RESEARCH AIM}

The aim of the present research is two-fold. The first aim was to investigate how individuals process belief-compatible and belief-incompatible arguments. The second aim was to investigate whether individuals' beliefs change after they read beliefcompatible and belief-arguments. Previous research indicates that pre-existing beliefs affect how individual process belief-relevant information and that pre-existing beliefs are maintained or strengthened after individuals read belief-compatible and beliefincompatible information (Edwards \& Smith, 1996; Kunda, 1990; Lord et al., 1979).

No research has yet investigated biased-assimilation and attitude polarisation within Āotearoa/New Zealand on the controversial issue being pre-service teacher beliefs about compulsory te reo Māori in New Zealand schools.

This study will investigate how individuals process belief-relevant information about a controversial issue. More specifically, this study will investigate how individuals process belief-relevant arguments and whether their beliefs change after they read beliefcompatible and belief-incompatible arguments. Previous research indicates that individuals experience cognitive dissonance when they read belief-inconsistent information, and as a result they apply different standards of evaluation to beliefconsistent and belief-inconsistent information, a process known as biased assimilation. Thus, it was predicted that individuals would be more likely to make supportive comments when they read belief-consistent arguments, whereas they would be more 
likely to make refutational comments when they read belief-inconsistent arguments.

Further, previous research indicates that individuals' beliefs become stronger after they read belief-relevant information. Thus, it was predicted that participants' beliefs would be maintained or become stronger after reading, an outcome known as beliefpolarisation.

\section{WĀHANGA 4: TE WĀHANGA TĀTAURANGA - QUANTITATIVE PHASE}

This section provides information regarding the methods used for the quantitative

phase of the study. The think-aloud method was used to gather student online processing of the supporting and opposing arguments for compulsory te reo Māori in New Zealand schools.

\subsection{Quantitative Methods}

Participants received task instructions and then read a think-aloud text that present arguments supporting and opposing a controversial issue in Āotearoa, New Zealand. All participants received the same instructions, materials and tasks, which described the purpose of the present study, explained the think-aloud task, and allowed them to reason through, and justify their position on the controversial topic. These materials were specifically designed to identify participants' pre-existing beliefs on the issue of compulsory te reo Māori in New Zealand schools, to examine if participants show examples of biased assimilation while reading belief-compatible and beliefincompatible arguments, and if participants beliefs showed an increase in polarisation after reading the arguments presented in the think-aloud text according to their preexisting beliefs.

Previous research has demonstrated that the think-aloud method provides useful insight for understanding participants' cognitive processes (Gill \& Nonnecke, 2012; Kucan \& Beck, 1997). Thinking-aloud is the process of saying aloud ones' thoughts' while reading a text in order to further understand the processes a participant may use to justify, reason and preserve pre-existing beliefs or attitudes (Kucan \& Beck, 1997). I used the think-aloud method for three reasons. First, this method provides researchers with participant online processing of information, online referring to participants moment-by-moment cognitive processing while reading text (McCrudden, 2012).

Second, when used in conjunction with belief-incompatible arguments participants are likely to experience cognitive dissonance and attempt to understand it, refute it or deny 
validity of the belief-incompatible argument (Chinn \& Brewer, 1998; McFalls \& CobbRoberts, 2001). Third, in relation to the current research it allows the researcher to identify which arguments (both supportive and opposing) generate positive connections from amongst pre-service teachers.

\subsection{Design and Participants}

Twenty-three university students enrolled in a pre-service teacher education program at a university located on the north island of New Zealand volunteered to participate in this study. There were 17 female and 6 males and the mean age of participants was 33.6. Table 1 presents the different ethnicities of the research participants'. It is important to note that although there were 23 research participants, many participants identified multiple ethnic roots that are displayed in the table below.

Table 1.

\begin{tabular}{l|l}
\hline Ethnic Identities & $N=$ \\
\hline New Zealand Pākehā & 9 \\
New Zealand European & 3 \\
New Zealander & 2 \\
Māori/ Cook Island/ Welsh & 1 \\
Māori (Ngāti Kahungunu, Ngāti & 1 \\
Pahauwera)/ British (Kent, England) & \\
New Zealand Pākehā (Irish, Welsh, & 1 \\
English) & 1 \\
Fijian/Samoan & 1 \\
New Zealand / Australian & 1 \\
Canadian & 1 \\
British White & 1 \\
European (Not NZ born) & 1 \\
Irish & \\
\hline
\end{tabular}

On the basis of responses to the initial topic belief scale, all 23 of the participants were proponents of compulsory te reo Māori in New Zealand schools.

The participants were enrolled in the final course of a postgraduate diploma of teaching. Prior to this course, participants had completed a course (Mātauranga Māori in Education) that focuses on developing pre-service teachers' awareness and understanding of te āo Māori (Māori worldview), and effective teaching and learning strategies that cater to the diversity of Māori within the Āotearoa, New Zealand educational context.

I applied purposive sampling to recruit participants. Before approaching these students, I approached the academic group director and the course coordinator for permission to recruit from this specific cohort of students'. The researcher presented the 
research topic and purpose to prospective participants at the beginning of two different lectures. Students' self-selected participation in the current study. They provided personal information (name, phone number, email address and preferred day and time) to be contacted for organising a date and time for participation in the study. Because of the nature of the research, and the primary researcher being Māori, non-Māori interviewers were made available if requested. No participant made specific requests for non-Māori interviewers. Participant identities are confidential.

\subsection{Materials}

\subsubsection{Belief measure task}

The topic beliefs scale began with the following prompt: "There has been a great deal of debate about whether te reo Māori (Māori language and customs) should be compulsory in New Zealand primary and secondary schools. Please circle a number below to indicate your agreement with the following statement". Participants stated their initial belief using a 9-point Likert-type scale $(1=$ very strongly disagree to $9=$ very strongly agree). Then they were given the following instruction, "Please explain the reasons behind your response using as much detail as possible. This is your opinion so there are no right or wrong answers. Don't worry about spelling or punctuation. You can also use the back of this sheet of paper if needed". Participants completed the topic beliefs scale and justification activity twice, both before and after the think-aloud task.

\subsubsection{Think-aloud task instructions}

Participants received the following instructions for doing the think-aloud task: "We are interested in investigating how people develop their opinions and what people think of information that they agree and disagree with. You will be presented a short passage that includes ideas in support of and in opposition whether te reo Maori should be compulsory in New Zealand primary and secondary schools. In order to understand how people develop their opinions, we need you to think out loud while you are reading. We would like you to say everything you are thinking out loud while you read the text. That is, please say out loud any thoughts that come to mind at any point during the reading. But in particular, whenever you see three stars $(* * *)$ after a sentence, we need you to comment out loud. Before we begin, you will have the opportunity to practice with a shorter passage." All participants received these instructions (see Appendix A) and were also provided with a practise think-aloud text on an unrelated topic in order to familiarise themselves with the think-aloud process (see Appendix B). 


\subsubsection{Text}

The text was 1,078 words and titled "Should Te Reo Māori be compulsory in New Zealand schools?” (see Appendix C). The text contained 10 arguments, five supporting the compulsory teaching of te reo Māori in New Zealand schools, and five opposing the compulsory teaching of te reo Māori. The text was interleaved such that an argument opposing compulsory te reo Māori was followed by an argument supporting the compulsory teaching of te reo Māori. Wiley (2005) found that use of an interleaved text can help readers compare and contrast opposing views on controversial topics.

\subsection{Procedure}

Participant consent was obtained before the study, along with demographics (age, gender, and ethnicity). The experiment was conducted one-on-one in pre-determined locations on the university campus. The procedure consisted of eight steps. First, participants were provided with an information sheet. Second, participants completed the first administration of the attitude measure task. Third, participants received task instructions for the think-aloud task. Fourth, participants practiced thinking aloud while they read the practice text. Fifth, participants read the actual text using the think-aloud method. Sixth, participants completed the second administration of the attitude measure task. Seventh, participants were interviewed using a semi-structured, open-ended set of questions (see Appendix E). Finally, all materials were collected and students were debriefed and dismissed.

\subsubsection{Ethical Approval}

Ethical approval was given through Victoria University of Wellington Human Ethics committee (see Appendix F). Before beginning the study, informed consent was obtained from participants after reading the information sheet (see Appendix G). They were informed on the procedures of the research task and that participation was voluntary. Participants were aware that they would complete a think-aloud task followed by a semi-structured interview. They were informed that their identity and comments would be confidential.

\section{WĀHANGA 5: NGĀ TUKUNGA TATAURANGA - QUANTITATIVE RESULTS} This section presents the results from the quantitative phase of the study. 


\subsection{Results: Quantitative Phase}

The first research question was: How do pre-service teachers process beliefrelevant arguments? The recorded think-aloud responses were transcribed and coded to evaluate how the participants processed the belief-relevant arguments. The second research question was: Do pre-service teachers' beliefs change after they read a balanced set to belief-compatible and belief-incompatible arguments? The responses to the prereading and post-reading belief measures were compared to determine whether participants' beliefs changed after they read the text.

\subsubsection{Think-alouds}

A 2 (type: supportive or refutational) x 2 (compatibility: belief-compatible or belief-incompatible) within-subject ANOVA was used to evaluate the think-aloud data. Means and deviations appear in Table 2.

The main effect of type was significant, $F(1,22)=4.14, M S E=3.41, p=.05, \eta^{2}=.158$. Participants made supportive comments $(M=7.0, S E=0.4)$ more frequently than refutational comments $(M=6.2, S E=.04)$. The main effect for compatibility was significant, $F(1,22)=4.97, M S E=1.26, p<.05, \eta^{2}=.184$. Participants made more comments at belief-compatible arguments $(M=3.4, S E=0.2)$ than at belief-incompatible arguments $(M=3.2, S E=0.2)$.

These main effects were qualified by a significant interaction effect between type and compatibility, $F(1,22)=397, M S E=3.78, p<.001, \eta^{2}=.947$. Follow-up tests used Tukey's HSD, which controls for family-wise error at the .05 level. Participants made supportive comments at belief-compatible arguments $(M=13.0, S E=0.6)$ and refutational comments at belief-incompatible arguments $(M=11.7, S E=0.7)$ more frequently than they made supportive comments at belief-incompatible arguments $(M=$ $1.0, S E=0.2)$ and refutational comments at belief-compatible arguments $(M=0.7, S E=$ 0.1 . No other differences were significant. In other words, when individuals made supportive comments, they predominantly did so while they read belief-compatible arguments. Conversely, when individuals made refutational comments, they predominantly did so while they read belief-compatible arguments.

Table 2. Type of Responses to Think-aloud text from Participants

\begin{tabular}{r|lrr}
\hline \multicolumn{2}{|c|}{} & \multicolumn{2}{c}{ TYPE } \\
\hline \multirow{3}{*}{ COMPATIBILITY } & & Supportive & Refutational \\
& Compatible & $13.0(3.0)$ & $0.7(0.7)$ \\
& Incompatible & $1.0(1.1)$ & $11.7(3.3)$ \\
\hline
\end{tabular}




\subsubsection{Topic beliefs}

A within-subject repeated-measures ANOVA was used to evaluate participants' topic beliefs before and after reading. Participants' post-reading beliefs $(M=8.2, S D=$ 1.0) were significantly stronger than their pre-reading beliefs $(M=7.9, S D=1.2), F(1$, $22)=6.82, p<.05, \eta^{2}=.237$. Thus, participants more strongly believed that te reo Māori should be compulsory after reading than before reading.

\section{WĀHANGA 6: QUALITATIVE METHODS}

Qualitative methods, such as participant interviewing are used by researchers to follow-up or explain initial quantitative findings (Creswell \& Clark, 2007; Igo, Bruning, \& Riccomini, 2009). In the present study, qualitative data was used to further explain why participants evaluated belief-compatible and belief-incompatible arguments differently and why participants' beliefs remained the same or became stronger after they read. Individual interviews were carried out immediately after participants completed the quantitative phase of the study (Igo et al., 2009; McCrudden, Magliano, \& Schraw, 2010).

\subsection{Participants}

All 23 participants were interviewed. Comparison of the pre- and post-reading topic belief measures indicated that six participants' beliefs became stronger, whereas 17 participants beliefs remained the same. Of these 17 participants, ten had marked the top level of support (i.e., 9 very strongly agree) on both the pre- and post-reading topic belief measures, thus it was not possible for them to change. The other seven participants had more moderate views that did not change (e.g., 7 agree on both the pre- and post-reading measure). All responses to the first interview question (i.e., Now that you have read various views about making te reo Māori compulsory, has your attitude towards this topic changed?), and follow-up prompts, were used for the qualitative analysis.

\subsection{Materials}

\subsubsection{Interview protocol}

Turner (2010) described semi-structured interviews as an effective tool that allows participants to express their perspectives and experiences. The interview protocol for the current research was designed to explore why participants reacted to belief- 
compatible and belief-incompatible arguments differently and why their beliefs remained the same or became stronger (see Appendix D).

\subsubsection{Procedure}

Individual interviews were completed immediately following the quantitative phase. This was done so that the participants could more easily recollect their thoughts from the think-aloud task. All participants were asked the same questions with variations only to account for comments made by the participant during the think-aloud task. Qualitative themes were analysed by two external researchers.

\subsection{Interview data analysis and results}

Verbatim transcriptions of interviewee responses were made and analysed using a three-stage process. The first stage was a reading of complete interview transcripts for all participants. The researcher listened to all audio recordings of the interviews and read the interview transcripts to develop a holistic sense of the data. The second stage involved re-reading all responses to the first interview question (Now that you have read various views about making te reo Māori compulsory, has your attitude towards this topic changed?) and extracting meaningful phrases that pertained to participants' beliefs. The researcher identified a wide-range of different responses to this question. For example, participant 5 replied, "No... I was fairly familiar with most of the arguments," participant 25 replied, "... the racism, the inequity in some of those statements and just the blatant ignorance," and participant 11 replied, "No... I already had quite strong views already." In the third stage the researcher used the qualitative data analysis program Nvivo 10 to classify participant responses into broader thematic categories (Burnard, 1991). For example, participant 16 replied, "Not really, in that I was already fixed on my idea," participant 31 replied, "Well, it was kind of fixed to start with", and participant 2 replied, "I was aware of most of the issues." These responses were classified as "preexisting beliefs.' Other thematic categories were 'personal experiences', 'belief-change', 'emotional response to arguments', 'positive response towards think-aloud task', 'New Zealand education system', and 'New Zealand specific reasons'.

\section{WĀHANGA 7: QUALITATIVE RESULTS}

This section presents an overview of the results from the qualitative data analysis. This qualitative data analysis further investigates the three groups that were identified from the quantitative data analysis: 1) belief maintenance (participants who showed no 
belief-change); 2) strengthening (participants whose beliefs became stronger); and 3) strong supporters (participants who indicated the maximum support of ' 9 ' both before and after reading). Two major patterns emerged across the three groups from the qualitative data analysis: individual factors and contextual factors. These patterns will be further discussed in this section.

\subsection{Introduction}

Three groups emerged from the quantitative data analysis. Group 1 beliefmaintenance (for example scored an eight on the pre-test and on the post-test). Group 2 were participants who showed strengthening of beliefs (for example scored a seven on the pre-test, and an eight on the post-test), and the third group are considered the strong supporters of the controversial issue who scored a nine on the pre-test and the post-test (nine was the highest number on the Likert-scale). This section describes the results from the qualitative analysis of interview data. This analysis focused on participants' responses to the first interview question and follow-up questions. The analysis further investigated participant responses for either experiencing belief-change, or not experiencing belief-change.

Analysis of participants' evaluation of belief-relevant arguments in the thinkalouds revealed to two key patterns: individual factors and contextual factors. Individual factors included themes such as: personal experiences, belief-change, emotional response to arguments in the think-aloud text, and pre-existing beliefs. Contextual factors included such things as: positive response towards think-aloud task, New Zealand education system, and New Zealand specific reasons. This also included overseas experience, equality for all curriculum areas and language learning.

It is important to note that although this analysis highlighted these key patterns, individual and contextual factors were highly related, interdependent and multifaceted. For example participants' justifications included sub-themes of social justice, equality, and anti-racism, which related to participant's own individual beliefs and social experiences.

\subsection{Analysis of Group 1 - Belief Maintenance}

Seven of the 23 participants scored indicated a number of 6 (somewhat agree), 7 (agree), or 8 (strongly agree) on the topic belief measure before and after reading; thus, showed no belief change (e.g., indicate an 8 before and after reading). Two participants indicated "6", one indicated "7", and four participants indicated " 8 " on the topic belief 
scale before and after reading. It is interesting to note that participants in this group identify as New Zealand Pākehā and New Zealander (see Table 3.)

Table 3. Belief Maintenance Ethnicities

\begin{tabular}{l|l}
\hline Ethnic Identities & $N=$ \\
\hline New Zealand Pākehā & 5 \\
New Zealander & 1 \\
\hline
\end{tabular}

It is interesting that although all participants in this group did not indicate belief change on the topic belief measure, one participant (\#19) provided the following response, which indicated that her beliefs had become stronger after reading: So, no not at all, if anything it's probably made it stronger. (\#19)

The sub-theme that emerged from this analysis that pertained to individual factors was: personal experiences. The sub-themes that pertained to contextual factors were: responses to arguments in the think-aloud text, New Zealand education system. It is important to note that one participant did not explain why he did not experience beliefchange. Therefore, this analysis will include data from six of the seven participants in this group.

\subsubsection{Individual factors: Personal experiences}

Analysis of interview data revealed that participant's personal experiences were powerful for affecting their reasoning and justifications. Three participants in this group shared personal experiences to justify their positions on the controversial issue. Further analysis of this data produced the following sub-themes: overseas experience, equality for all curriculum areas and language learning.

Participants in this group shared experiences of travelling overseas to further justify their position on the issue:

A lot of people sort of argue that 'Oh you know, English is a universal language, it's becoming more and more spoken', but yeah, I tell you what, I've travelled extensively through Europe and Europe is supposed to be sort of this continent where everyone speaks English, so not true! So not true! If you go to the most touristy restaurant in Rome, maybe you'll find an Italian that can speak English, but otherwise, just no. (\#20)

Participants in this group understood the plight for equality for te reo Māori in New Zealand based on their own experience within the education system: 
I teach health as well as science and so it's kind of like conflicting because health education is also undervalued in New Zealand and I think that should be important along with te reo Māori and so, um, like, just fighting for the time is quite hard, so I can see that but I still feel that Mãori is an important subject so it should be given that time. (\#22)

This participant shared her own past and personal experiences of the value of learning other languages and shared how te reo Māori was not a language offered at the college she had attended:

I studied languages at school, um, not Māori, it wasn't offered, it wasn't offered at my school, but, um, I did study languages, not because I thought to myself 'Hey, these are gonna be super useful!' Just because they were my favourite subjects, I loved learning them. (\#20)

\subsubsection{Contextual factors: Positive response towards think-aloud task}

Analysis of the interview data revealed that participants' regularly responded to arguments from the think-aloud text. Some of the arguments were controversial in nature. Six of the seven participants referred to the arguments presented in the thinkaloud text, in some form. The analysis of this data revealed the following sub-theme: balanced text,

Participants in this group acknowledged that the think-aloud text provided a balanced view of the controversial issue. However, beliefs did not change:

My main, yeah sort of overall opinions stayed the same but it was um, it was still cool thinking, I mean it was really valuable thinking through all of the different arguments people present so, yeah it didn't change my views but it gave, um sort of, um, I dunno, gave them more texture, gave them different elements. (\#26)

I guess it made me aware of different, like, points of argument, you know for and against, like both sides, but it hasn't changed it because I still feel that it's really important. (\#22)

Participants in this group also acknowledged some support to belief-incompatible argument within the think-aloud text: 
I guess make sense is the um, the idea of it, well, the argument was that it takes up time that could be spent on, on other languages, on other subjects... I'm all for te reo Māori being compulsory in, in primary schools, and if it were to be compulsory in secondary schools um, I probably wouldn't like to see it compulsory beyond year 10, um, but I think it should be a compulsory option in all schools. I mean there are still schools in the country that don't even offer it at secondary level and I think that that's an issue. (\#20)

Some of the participants most likely did not experience belief-change because they were already aware of these arguments prior to participating in the think-aloud task: Because I was fairly familiar with most of the arguments I kinda heard those before and I was sort of anticipating them and thus they didn't really change my, um, attitude. (\#5)

\subsubsection{New Zealand Education System}

Interview analysis indicated that participants were influenced by contextual factors such as an awareness of the pressures placed on college students with NCEA qualifications, and choosing career pathways. Participants also made suggestions for the implementation of compulsory te reo Māori in New Zealand schools:

I didn't see that much value but I guess like, when, um, they say like, the whole thing about they'd rather their students learn important subjects, like necessary subjects and they think that Māori isn't necessary, like, I guess, especially as a secondary school teacher like with NCEA and that sort of thing, um, and like those career kind of paths, then, I can see, but the time pressure is already so much there, just for even the core subjects. (\#22)

I think including it in primary schools will kind of open, primary school students up to kind of a new realm as well, you know you do your English, you do your maths, a lot of primary schools will do, you know, you do at some point some social studies and science and that sort of thing as well... I think it would be quite, it would be quite beneficial to languages as a whole if um, if it's compulsory for primary, primary aged kids to start learning, start learning one right from the beginning. Give them an appreciation of what it is to learn a language as a subject. (\#20) 


\subsection{Analysis of Group 2 - Belief-Change}

Six of the 23 participants showed an increase of support for the compulsory teaching of te reo Māori in New Zealand schools. They experienced belief-change. Five participants shifted one level on the scale (e.g., 7 to 8), and one participant shifted two levels on the scale (i.e., 6 to 8 ). It is interesting to note that four participants of this group identify differently as New Zealand citizens, with one identifying Pasifika heritage (see Table 4).

Table 4. Belief-change Ethnicities

\begin{tabular}{l|l}
\hline Ethnic Identities & $N=$ \\
\hline New Zealand Pākehā & 2 \\
New Zealand European & 1 \\
Māori/ Cook Island/ Welsh & 1 \\
New Zealand Pākehā (Irish, Welsh, & 1 \\
English) & 1 \\
Fijian/Samoan & \\
\hline
\end{tabular}

Further analysis of the interview data revealed the following major themes: beliefchange, personal experiences, emotional response to arguments in the think-aloud task. It is interesting to note that the themes emerging from this group only pertained to individual factors.

\subsubsection{Individual factors: Belief-change}

All participants in this group had stronger beliefs after they read the text. For instance, when asked to explain why her beliefs became stronger, one participant replied:

It's probably a bit stronger but, it's still fairly similar to what it was before... So probably will tend to agree a little more strongly to making it more compulsory. (\#32)

It is important to note that although one participant reported a change in beliefs, the justification for this change focused more on the personal journey this participant was undertaking, rather than the text, per se:

Q: Now that you have read various views about making te reo Māori compulsory, has your attitude towards this topic changed?

Um, I think the first time when I wrote it, I put um that if I actually knew more te reo, then I'd probably, my mark that I gave would've been higher. I think um, mine's just more about my own journey in terms of the language. (\#13) 


\subsubsection{Individual factors: Personal Experience}

As teacher training students, participants often referred to experiences during teaching experience with their associate teacher, or visiting lecturers when asked about whether their beliefs had changed:

On TE [teaching experience] I was told that... I didn't use enough te reo in terms of all the curriculum subjects... I used a lot, but it was only what I knew which was the greetings and commands, which I use with my kids. Um, and I told her that when it flows off my tongue then I'll be confident enough to use it with, in terms of the curriculum subjects. So, my idea is that, um, once I get my own class, I'll start off with one subject and then once I get that, that hang of that one, then I'll add another, like reading and carry on like that... Both of my TE's I had to leave behind the [Māori] commands that I used and write them down for them [associate teacher] because they were both pākehā. So, um, so that felt good, that I'd gone in with what I knew, as little as it is, it made me feel better that I did know some. (\#13)

\subsubsection{Emotional response to arguments in the think-aloud text}

Most participants responded negatively towards the belief-incompatible arguments in the text. The following quote illustrates one such reaction:

Yeah, the racism, the inequity in some of those statements and just the blatant ignorance, like, the reality that a lot of people, it's as if some of the people making those statements are not even seeing Māori, like they're not even actually allowing them to exist by the mere statements that they are making. Yeah um, it causes quite a deep rage in me and for some reason I, well not for some reason but you know, as a pākehā I have a whole lot of empathy for that sort of situation... I think is so brutal and horrible, to be denied of what you are. To be denied of your language, to be denied of your culture is um, that's criminality... So I do, I kind of acknowledge that there's this whole history of um, really painful injustice and um, yeah so it's about how do we address that positively now. (\#25)

\subsection{Analysis of Group 3 - Strong Supporters}

Ten of the 23 participants were considered very strong supporters of compulsory te reo Māori in New Zealand schools. They indicated a "9" (very strongly agree), the maximum on the 9-point scale, before and after reading. It is interesting to note that of 
this group four participants identify as not being from New Zealand, the remaining six identify differently as New Zealand citizens (see Table 5).

Upon further analysis of group, three participants indicated that their beliefs became stronger after they read, although their explanations were somewhat short. To illustrate, when asked, "Now that you have read various views about making te reo Māori compulsory, has your attitude towards this topic changed?" participant 28 replied, "Not really, maybe it has strengthened it... reading some of those arguments for why te reo Māori shouldn't be compulsory just really annoys me."

Table 5. Strong Supporter Ethnicities

\begin{tabular}{l|l}
\hline Ethnic Identities & $N=$ \\
\hline New Zealand Pākehā & 2 \\
New Zealand European & 1 \\
New Zealander & 1 \\
Māori (Ngāti Kahungunu, Ngāti & 1 \\
Pahauwera)/ British (Kent, England) & \\
New Zealand / Australian & 1 \\
Canadian & 1 \\
British White & 1 \\
European (Not NZ born) & 1 \\
Irish & 1 \\
\hline
\end{tabular}

Of the ten participants in this group, nine explained why they strongly supported compulsory te reo Māori in New Zealand schools. The sub-themes that emerged from this analysis were: personal experiences, emotional response to arguments in the thinkaloud text, and pre-existing beliefs. The sub-themes relating to contextual factors were: positive response towards think-aloud task and New Zealand specific reasons. Analysis of these nine participants revealed the following themes: Personal experiences, New Zealand specific reasons, and responses to think-aloud text.

\section{Individual factors}

\subsubsection{Personal Experiences}

Participant's personal experiences had a powerful influence on their justifications. Four of the ten participants referred to their own personal experiences to justify their support for compulsory te reo Māori in New Zealand schools. These experiences revealed the following sub-themes: whakapapa (family links), teacher training, positive 
experiences with Māori, and migrating to New Zealand. Examples of quotes are provided to illustrate these sub-themes.

Personal experiences included references to whakapapa (family links) to the Māori language and customs as to participant's reasoning for further supporting compulsory te reo Māori in schools:

I think it's especially because I'm personally attached to this issue... it has personal relevance to me as a teacher, and as a Māori person who doesn't have much of their own language, so I think it really does concrete my own opinion. (\#24)

Personal experiences during their course of studying to become a teacher was evident in justifications, and how these experiences further solidified their position on compulsory te reo Māori:

Um, and I guess it has been the studies and experiences of this year for me, it was like 'We all need it'. I suppose... it was the very first KURA [paper] it was (tutor name removed) talking around his experiences and... the way he communicates, it made it apparent that the, the value in being able to reciprocate, to be able to communicate, in Māori it was like... even if you don't use it much, that's not the point, you, it's, is it about respect? It sort of is... for me, it's about connection. Um, I got that in a non-verbal way, I got my understanding in a non-verbal way ... I was like 'Oh, yeah, that actually, that's another layer that you need'. (\#31)

Positive personal experiences with the Māori culture and people was also seen by participants of this group to be important in justifications:

Definitely the um, the valuing and that of Māori culture, because I grew up, my sister's ex-partner and my other sister's current partner are both Māori, and I grew up with my niece as half Māori, I've always though it's a fantastic culture that values the right thing so, children caring for each other, love, you know, being a whole well developed person. (\#23)

The theme personal experiences also included an experience from a migrant to Aoteroa, and first introductions to te reo Māori me ōna tīkanga:

When I arrived in the country we were made aware that te reo was taught to some degree in primary, and intermediate levels... from the comments I remember it did have this sort of tokenistic quality to it... And while something may be better than anything, than nothing, sorry. I do think it needs to be done with a lot more conviction, commitment and um, complexity 
or completeness, and tied into um, to te ao Māori, and the actual deep, deep cultural um, ideas not just things like kapa haka and which, are fun but a very surface to me, uh yeah. Because the language brings with it ideas and concepts that may not translate um, easily into other languages, and other cultures and need to be explained and looked into. Um, yeah, and yeah as I say I think it's you know, it's been a great gap in my understanding of New Zealand society. (\#15)

\subsubsection{Emotional response to arguments in the text}

Participants also had emotional reactions to the arguments in the text. Some of the arguments were controversial in nature. All ten participants in this group referred to the arguments presented in the think-aloud text, in some form. Further analysis of this data revealed the following sub-themes: Awareness of the think-aloud arguments, responses to belief-incompatible arguments, and pre-existing beliefs.

Participants in this group gave reasoning that linked closely with an awareness of the arguments supporting and opposing compulsory te reo Māori in New Zealand schools prior to participating in the think-aloud task:

I'd had an awareness of all the arguments, the pro's and the con's and so much of the debate around this particular topic, seems to me have, to have it's roots, the debate against, seems to have it's roots in racism. (\#31)

In response to belief-incompatible arguments, participants gave the following justifications:

Yeah, the ones against it just seemed purely racist in a lot of ways to me.

As soon as I started reading some of those things that I'd heard before I was like 'you're wrong, you're wrong', you're just plain wrong. (\#24)

But to me I've always felt like, the real, $\mathrm{mmm}$, debate, or the real reason why it should be compulsory sort of wasn't touched on. (\#3)

The following quote represents the justification a participant used when encountered with a belief-incompatible argument the participant agreed with:

The only one (belief-incompatible argument) that um, resonates at all is the one about multiculturalism, um, and I'd think that's only just as a warning 
really, not to ignore the other elements in our society, but I don't think it, not to disenfranchise them. I don't think, but I don't think it affects the argument that Màori should be taught, te reo and tīkanga should be taught in New Zealand schools. (\#15)

\subsubsection{Pre-existing beliefs}

Participants in this group strongly linked their position post-think aloud task to their pre-task belief position, stressing their support for compulsory te reo Māori in New Zealand schools. Below are two examples of the responses participants gave:

I was already fixed on my idea that it was, just what its really done is reinforced those ideas. The idea that I already had, and yeah, that it's really important. (\#16)

I still really strongly think it should be compulsory te reo should be compulsory in schools. (\#18)

\section{Contextual factors}

\subsubsection{New Zealand specific reasons}

The interview data revealed themes related to Āotearoa, New Zealand that provided the backdrop for this controversial issue. Four of the ten participants made comments relating to New Zealand society and politics. Further analysis of this data revealed the following sub-themes: New Zealand society, the value of te reo Māori and tīkanga for non-Māori.

Participants in this group commented on the bicultural and multicultural nature of the New Zealand society:

Maybe I think the text could've also had more about um just, how we are more a bicultural country because it didn't really say, it didn't really say that we are a bicultural country and it didn't really talk a lot about the treaty. (\#28)

The comment is given as a warning not to ignore the multicultural fractions of the New Zealand society, while teaching compulsory te reo Māori in schools:

The only one that ... resonates at all is the one about multiculturalism, um, and I'd think that's only just as a warning really, not to ignore the other elements in our society, but I don't think it, not to disenfranchise them. I 
don't think... it affects the argument that Màori should be taught, te reo and tīkanga should be taught in New Zealand schools. (\#15)

Participants in this group also make reference to learning te reo Māori me ōna tîkanga being valuable for non-Māori:

They (non-Māori) have such a lack of awareness and understanding of, it's like on another planet or rather for them it must be like Māori language is on another planet, like 'they're on their planet we're cool, what's, what's the issue? We're happy.' They may even, I suspect and I ... would've been in this, this boat, um, not so long ago that, there'd be a chunk of people that'd think it was really, really important that Māori learnt te reo, but never got the connection as to why they needed to, or their kids needed to... but they (Màori) actually plug into this whole pulsing rhythm that the land has, that most of us or many people don't see and I only sort of see bits every now and again. 'Oh my God! I've missed something there' ... the way you communicate is so important in that, and language is part of that. (\#31)

\subsubsection{Response to think-aloud task}

Some participants in this group referred to the new learning or deepening of understanding of the different arguments through the think-aloud task:

I guess I maybe slightly have a better understanding of different arguments for and against. (\#18)

\subsection{Cross Group Analysis}

Three common themes were identified through the cross group analysis: Individual based themes, educational based themes, and New Zealand based themes. The cross group analysis includes themes that emerged from the remainder of the qualitative interview phase (including responses to question one in the interview). These themes assist in building a more comprehensive picture of the similarities between the three groups, as well as highlighting the slight differences between the Belief Maintenance group and the two: belief-change, and strong supporters groups.

Overall, there were more similarities than differences across the three groups. Of the fifteen themes all three groups matched with seven themes. Of the remaining eight themes the belief-change group and strong supporters group matched together with five of those themes. It is interesting to note that there are more similarities than differences between the two aforementioned groups. It is also important to note that although this 
analysis highlighted these key patterns, individual and contextual factors were highly related, interdependent and multifaceted.

\subsubsection{Individual based themes}

This included personal experiences that occurred prior to enrolling in the postgraduate diploma teaching degree, as well as experiences that occurred during postgraduate diploma studies (see Table 6). It also included comments participants made regarding arguments and statements made during the think-aloud task.

\subsubsection{Educational based themes}

Although only one theme was identified, the attitudes and experiences of these participants during their post-graduate diploma studies have expressed concerns participants hold regarding the authenticity of their cultural experiences within the teacher training system as well as the attitudes and beliefs of other students' towards the te reo Māori component of the graduating teacher standards (see Table 7). 
Table 6. Individual based themes. Responses to Question 1 of the Interview (See Appendix D)

\begin{tabular}{|c|c|c|c|}
\hline Themes & Belief Maintenance & Belief-change & Strong Supporters \\
\hline \multicolumn{4}{|c|}{$\begin{array}{l}\text { Individual based themes } \\
\text { Response to Question } 1\end{array}$} \\
\hline $\begin{array}{l}\text { Personal } \\
\text { Experiences }\end{array}$ & $\begin{array}{l}\text { 'I studied languages at school, not Māori it wasn't } \\
\text { offered at my school, but, um, I did study } \\
\text { languages, not because I thought to myself 'Hey, } \\
\text { these are gonna be super useful!' Just because } \\
\text { they were my favourite subjects, I loved learning } \\
\text { them' (\#22) }\end{array}$ & $\begin{array}{l}\text { 'And, um, like on teaching experience I was told } \\
\text { that I didn't use enough te reo in terms of all the } \\
\text { curriculum subjects... [but on] both of my } \\
\text { teaching experiences I had to leave behind the } \\
\text { commands that I used... because they were both } \\
\text { pākehā' (\#13) }\end{array}$ & $\begin{array}{l}\text { 'I grew up, my sisters ex partner and my other } \\
\text { sisters current partner are both Māori, and I grew } \\
\text { up with my niece as half Māori. I've always } \\
\text { though it's a fantastic culture that values the right } \\
\text { thing so, children caring for each other, love, you } \\
\text { know, being a whole well developed person' (\#23) } \\
\text { 'I'm personally attached to this issue, and I have, } \\
\text { it has personal relevance to me as a teacher, and } \\
\text { as a Mäori person who doesn't have much of their } \\
\text { own language, so I think it really does concrete } \\
\text { my own opinion' (\#24) }\end{array}$ \\
\hline $\begin{array}{l}\text { Think-aloud text } \\
\text { re-affirming } \\
\text { pre-existing } \\
\text { beliefs }\end{array}$ & $\begin{array}{l}\text { 'Ah, no, not at all. If anything it's kind of } \\
\text { reiterated, it's... actually put it down in words, so } \\
\text { I can actually see it and go, well, yeah that's what } \\
\text { I was trying to, kind of get at... So, no not at all, if } \\
\text { anything it's probably made it stronger' (\#19) }\end{array}$ & $\begin{array}{l}\text { 'If you're asking if I... changed my mind in terms } \\
\text { of not supporting this topic, no I haven't. It is } \\
\text { actually reaffirmed it' (\#14) }\end{array}$ & $\begin{array}{l}\text { 'I was already fixed on my idea that it was, just } \\
\text { what its really done is reinforced those ideas. The } \\
\text { idea that I already had, and yeah, that it's really } \\
\text { important' (\#16) }\end{array}$ \\
\hline $\begin{array}{l}\text { Emotional } \\
\text { response to } \\
\text { arguments in the } \\
\text { think-aloud text }\end{array}$ & & $\begin{array}{l}\text { 'Yeah, the racism, the inequity in some of those } \\
\text { statements and just the blatant ignorance... some } \\
\text { of the people making those statements are not } \\
\text { even seeing Máori. Like they're not even allowing } \\
\text { them to exist' (\#25) }\end{array}$ & $\begin{array}{l}\text { 'Yeah, the ones against it just seemed purely racist } \\
\text { in a lot of ways to me' (\#12) }\end{array}$ \\
\hline $\begin{array}{l}\text { Positive response } \\
\text { towards think- } \\
\text { aloud task }\end{array}$ & $\begin{array}{l}\text { 'My main, yeah sort of overall opinions stayed the } \\
\text { same but it was um, it was still cool thinking, I } \\
\text { mean it was really valuable thinking through all of } \\
\text { the different arguments people present so, yeah it } \\
\text { didn't change my views but it gave, um sort of, um, } \\
\text { I dunno, gave them more texture, gave them } \\
\text { different elements' (\#26) }\end{array}$ & & \\
\hline Belief-change & & 'It's probably a bit stronger' (\#32) & \\
\hline
\end{tabular}


Table 7. Educational Based Themes, responses made in the rest of interview

\begin{tabular}{|c|c|c|c|}
\hline Themes & Belief Maintenance & Belief-change & Strong Supporters \\
\hline $\begin{array}{l}\text { Post-graduate } \\
\text { teacher training } \\
\text { program }\end{array}$ & $\begin{array}{l}\text { 'I mean the last paper we did was all about sort of } \\
\text { acknowledging the Treaty of Waitangi and our } \\
\text { sort of um, obligations under it and how we } \\
\text { should sort of implement those in the classroom... } \\
\text { one of the ways of showing you were honouring } \\
\text { the treaty would be to use like te reo, me ona } \\
\text { tikkanga' (\#5) }\end{array}$ & $\begin{array}{l}\text { 'Part of teaching experience you had to use te } \\
\text { reo... I think they're saying tokenistic because } \\
\text { when they're [teacher training students'] actually } \\
\text { pronouncing it, it's because they have to, and } \\
\text { whether they pronounce it correctly or not it's um, } \\
\text { yeah, it's cringe sort of material when it's not, not } \\
\text { said properly' (\#13) }\end{array}$ & $\begin{array}{l}\text { 'I suppose it was a bit of a, negative comment on } \\
\text { the program... grad dip, um, teaching program, } \\
\text { but, you know I got a sense... they expected us to } \\
\text { fulfil the Māori teaching component and it was } \\
\text { sort of like... you're fine tick that box... in many } \\
\text { cases just that, associate teachers or, or busy } \\
\text { lecturers, didn't really care... in many cases the } \\
\text { argument for not doing it has been what's } \\
\text { perpetuated' (\#3) }\end{array}$ \\
\hline
\end{tabular}


Table 8. New Zealand based themes. Response to Question 1 (see Appendix D)

\begin{tabular}{|c|c|c|c|}
\hline \multicolumn{4}{|c|}{ New Zealand based themes } \\
\hline \multicolumn{4}{|c|}{ Response to Question 1} \\
\hline $\begin{array}{l}\text { New Zealand } \\
\text { curriculum and } \\
\text { education system }\end{array}$ & $\begin{array}{l}\text { 'I guess, especially as a secondary school teacher } \\
\text { like with NCEA and that sort of thing, um, and like } \\
\text { those career kind of paths, then, I can see, but the } \\
\text { time pressure is already so much there, just for } \\
\text { even the core subjects' (\#22) }\end{array}$ & $\begin{array}{l}\text { 'It should be learnt at schools, but not to the } \\
\text { extent of having to do it um, in-depth up to year } \\
\text { 13. Um, but I guess after reading that I probably } \\
\text { saw quite a few good arguments for it, so... agree } \\
\text { a little more strongly to making it more } \\
\text { compulsory' (\#32) }\end{array}$ & $\begin{array}{l}\text { 'When I arrived in the country we were made } \\
\text { aware that te reo was taught to some degree in } \\
\text { primary, and intermediate levels, and um, but it } \\
\text { did have, from the comments I remember it did } \\
\text { have this sort of tokenistic quality' (\#15) }\end{array}$ \\
\hline New Zealand & & & $\begin{array}{l}\text { 'Maybe I think the text could've also had more } \\
\text { about um just, how we are more a bicultural } \\
\text { country because it didn't really say, it didn't } \\
\text { really say that we are a bicultural country and it } \\
\text { didn't really talk a lot about the treaty' (\#28) }\end{array}$ \\
\hline \multicolumn{4}{|c|}{ Rest of the Interview } \\
\hline $\begin{array}{l}\text { Response to New } \\
\text { Zealand Politics }\end{array}$ & $\begin{array}{l}\text { 'Ok, Mr. Don Brash... just seeing that name raises } \\
\text { some ire in me... I don't know if he really believes } \\
\text { these things... It's the argument used by fascist } \\
\text { totalitarians and uh, not to put Mr. Brash in uh, in } \\
\text { that category... I fear the reasons behind those } \\
\text { arguments are not for the wonderful utopian } \\
\text { picture that perhaps it, it sort of is framed in I } \\
\text { suppose' (\#35) }\end{array}$ & $\begin{array}{l}\text { 'I supported the Fijian language be made } \\
\text { compulsory in Fijian schools... they tried to make } \\
\text { it at one stage and then we had a coup... It was } \\
\text { more because of the political situations got in the } \\
\text { way... we were hoping that Fijian and Hindi were, } \\
\text { because they're recognized as two national } \\
\text { languages... that represented the identity of Fiji' } \\
(\# 14)\end{array}$ & $\begin{array}{l}\text { 'I'm more inclined to, to agree with uh, a the } \\
\text { university lecturers then I am with a politician to } \\
\text { be honest' (\#11) } \\
\text { 'I mean Don Brash saying, oh well, you know, } \\
\text { 'we're one country with many people, 'that's } \\
\text { really easy for a middle class, middle aged white } \\
\text { man to say' (\#12) }\end{array}$ \\
\hline $\begin{array}{l}\text { New Zealand } \\
\text { bicultural } \\
\text { country }\end{array}$ & $\begin{array}{l}\text { 'I think it would be valuable for us as a country } \\
\text { um, to, to be able to communicate in both } \\
\text { languages more effectively so we understand each } \\
\text { other, more effectively, slightly better than we do } \\
\text { currently. Um, to get an understanding of another } \\
\text { way of looking at the world' (\#35) }\end{array}$ & $\begin{array}{l}\text { 'And, how we should um, yeah see ourselves or } \\
\text { locate ourselves within um, the bicultural aspect } \\
\text { of New Zealand identity? ... I think New Zealand } \\
\text { is a bicultural country, with multicultural people' } \\
\text { (\#14) }\end{array}$ & $\begin{array}{l}\text { 'I just think that te reo Māori should be } \\
\text { compulsory, and I think we've gone over why I } \\
\text { think it should be, very important to show respect } \\
\text { for your own identity, your own culture, and we do } \\
\text { live in a bicultural nation' (\#16) }\end{array}$ \\
\hline
\end{tabular}




\begin{tabular}{|c|c|c|c|}
\hline $\begin{array}{l}\text { New Zealand } \\
\text { colonisation and } \\
\text { historical issues }\end{array}$ & $\begin{array}{l}\text { 'Well it's an official language, it's a pretty } \\
\text { significant part of our heritage so, it's still about } \\
\text { understanding our country's past and yeah' (\#2) } \\
\text { 'I mean, when we colonized, well, when the } \\
\text { Europeans colonized, the Māori, they kinda like, } \\
\text { screwed them over, so they are entitled to some } \\
\text { privileges' (\#22) }\end{array}$ & $\begin{array}{l}\text { 'I do, I kind of acknowledge that there's this } \\
\text { whole history of um, really painful injustice and } \\
\text { um, yeah so it's about how do we address that } \\
\text { positively now' (\#25) }\end{array}$ & $\begin{array}{l}\text { 'If you take away the resources of pretty much an } \\
\text { entire race and then expect them to have the same } \\
\text { education, and the same education outcomes and } \\
\text { the same funds, then, I mean it's just not the way } \\
\text { it works... Yeah, because of colonialism I don't } \\
\text { see those things as preferential treatment... my } \\
\text { grandparents had their language literally beaten } \\
\text { out of them and that's not preferential treatment. } \\
\text { The fact that I have to now pay to learn my own } \\
\text { language, that isn't preferential treatment either } \\
\text { (\#24) } \\
\text { 'My niece's grandmother, on her father's side, ah, } \\
\text { she didn't speak English until she was } 5 \text { and she } \\
\text { went to school and she got strapped for speaking } \\
\text { Māori at school. But it's because she literally did } \\
\text { not know how to speak English' (\#23) }\end{array}$ \\
\hline $\begin{array}{l}\text { Te Tiriti } \overline{0} \\
\text { Waitangi - } \\
\text { Treaty of } \\
\text { Waitangi }\end{array}$ & & $\begin{array}{l}\text { 'When it [Treaty of Waitangi] was signed there } \\
\text { weren't all the other cultures that are here now... } \\
\text { If there was to be another, sort of multicultural } \\
\text { document signed, then that would be different, but } \\
\text { there hasn't been' } \# 32 \text { ) }\end{array}$ & $\begin{array}{l}\text { 'Because Mãori does have a unique position } \\
\text { because of, um, the principles of the Treaty of } \\
\text { Waitangi, so yeah we do need to privilege it. I } \\
\text { think that's a reason for it, not against it' (\#12) }\end{array}$ \\
\hline $\begin{array}{l}\text { Te Reo Māori } \\
\text { unique to } \\
\text { New Zealand }\end{array}$ & & $\begin{array}{l}\text { 'I think it's just useful in terms of being, having } \\
\text { any language is useful but, in particular your } \\
\text { native language should be the one you learn first' } \\
\text { (\#6) }\end{array}$ & $\begin{array}{l}\text { 'It wasn't till I went overseas uh, and started } \\
\text { working in the UK, that I, uh sort of realized how } \\
\text { special and uh, and, unique Māori was to New } \\
\text { Zealand'(\#11) }\end{array}$ \\
\hline $\begin{array}{l}\text { Our National } \\
\text { identity }\end{array}$ & & $\begin{array}{l}\text { 'It's about... knowing who you are as well, and } \\
\text { knowing your identity and the fact is, uh, Māori } \\
\text { culture and Máori language is part of New } \\
\text { Zealand's identity... and to deny that is to deny } \\
\text { yourself as well' (\#14) }\end{array}$ & $\begin{array}{l}\text { 'I'm not saying it's not here in New Zealand but } \\
\text { again you're all, we are all New Zealanders... } \\
\text { embrace Máori language and culture is... making } \\
\text { New Zealand a stronger country as opposed to } \\
\text { people thinking individually about what it will do } \\
\text { for them' (\#3) }\end{array}$ \\
\hline
\end{tabular}




\subsubsection{New Zealand based themes}

This included a diverse range themes specifically relating to New Zealand and participants heavily referred to themes based on New Zealand to further elaborate postreading position (see Table 8). These themes help build a more comprehensive picture on how these participants reason their positions, and include critiques of the New Zealand education system, our heritage and history, the Treaty of Waitangi, New Zealand's bicultural make-up, New Zealand politics, our national identity and the unique place te reo Māori has in New Zealand.

\subsubsection{Conclusion}

Overall, there were more similarities between the three groups post-reading justifications. Participants gave a range of reasoning for their post-reading position. Although, it is interesting to note that there were more instances when the belief-change group and strong supporters matched in their reasoning, there were also instances where the three groups shared the same themes.

\section{WĀHANGA 8 KAUPAPA KŌRERO - DISCUSSION}

This mixed methods study was designed to investigate how pre-service teachers evaluate belief-compatible and belief-incompatible arguments and whether their beliefs

change after they read belief-compatible and belief-arguments on a controversial issue in Āotearoa, New Zealand.

The initial quantitative analysis revealed that when individuals made supportive comments, they predominantly did so while they read belief-compatible arguments. Conversely, when individuals made refutational comments, they predominantly did so while they read belief-compatible arguments. The quantitative analysis also revealed that collectively, participants' topic beliefs became stronger after reading. However, some participants demonstrated belief-change, while others did not. I was interested in further investigating why some students developed stronger beliefs, whereas other beliefs remained the same after reading. Initially when attempting to mix the quantitative and qualitative data two groups were identified, participants who expressed strong emotive responses to arguments to question one of the interview, and those that did not express strong emotive responses to the interview question. The plan was to compare and contrast the reasoning used by each group (emotive and non-emotive), however, the general themes were too similar between the two groups to draw any reasonable 
conclusion. Therefore, the researcher will attempt to discuss the quantitative and qualitative findings generally with some thoughts of how each affects the other. This was also the case with other identified themes (re-affirming pre-existing beliefs, personal experiences, and references to the New Zealand educational curriculum), the data revealed no conclusive findings that reveal new understanding.

The purpose of the qualitative phase was to gain in-depth understanding into participants' justifications for why they did or did not experience belief-change. In the qualitative phase, interviews were carried out directly after the quantitative phase to investigate post-reading beliefs. The qualitative interviews revealed two overall sets of factors: individual factors and contextual factors. Themes included: personal experiences, New Zealand specific reasoning, and emotional responses to the think-aloud arguments.

These quantitative and qualitative findings are consistent with previous research within this field. This study supports Lord et al. (1979) claim that participants are likely to defend pre-existing beliefs according to their pre-existing beliefs and they will refute belief-incompatible arguments quickly and accept belief-compatible arguments.

Participants in this study indicated that they experienced biased assimilation and attitude polarisation when encountering belief-incompatible arguments (Lord et al., 1979).

Belief-incompatible arguments were heavily scrutinized by the participants of this study, giving a higher number of refutational comments for belief-incompatible arguments similar to those who participated in Edwards and Smith (1996) study.

The current research has highlighted three major findings indicating how preservice teachers respond towards both supporting and opposing arguments for compulsory te reo Māori in New Zealand schools.

\subsection{Supportive comments for belief-compatible arguments}

Quantitatively most participants gave more supportive comments for beliefcompatible arguments. Of the 23 participants in the current study 15 participants gave more supportive comments for belief-compatible arguments than refutational comments for belief-incompatible arguments. It is interesting to note that 12 of the 15 participants were also in the belief strengthening and strong-supporters groups.

Most participants were satisfied with arguments in the think-aloud text that supported the unique position of te reo Māori and tīkanga Māori in New Zealand and agree that this knowledge should be given higher prominence within the New Zealand 
education system. Through further qualitative analysis these themes were identified and further elaborated. Overall, participants' reasoning was more on a patriotic level, with themes such as New Zealand politics, New Zealand colonisation and historical issues, Treaty of Waitangi, and the development of a national identity that includes te reo Māori. Participant reasoning was in-depth and covered a range of themes that showed a higher level of cognitive strategies used during both the think-aloud task and interview.

These findings were consistent with previous research on biased-assimilation and belief polarisation. Previous research (Corner et al., 2012; Lord et al., 1979; Plous, 1991) stipulated that participants would respond positively towards belief-compatible arguments and rate these arguments stronger than belief-incompatible arguments. Plous (1991) found that participants focus on arguments that strengthen pre-existing beliefs.

\subsection{Refutational comments for belief-incompatible arguments}

Quantitatively, four of the 23 participants gave more refutational comments for belief-incompatible arguments than supportive comments for belief-compatible arguments. It is interesting to note however, that there was only a small margin of difference between this group and those that gave more supportive comments for beliefcompatible arguments (see Table 7).

Given that the reasoning used by the three groups identified in the quantitative phase are very similar and the difference between the groups at this level are marginal the challenge lies in identifying credible reasons for these differences.

Table 7.

\begin{tabular}{c|ccc}
\hline Participant & $\begin{array}{c}\text { Supportive } \\
\text { comments for } \\
\text { belief-compatible } \\
\text { arguments }\end{array}$ & $\begin{array}{c}\text { Refutational } \\
\text { comments for } \\
\text { belief-incompatible } \\
\text { arguments }\end{array}$ & Difference \\
\hline 2 & 10 & 11 & -1 \\
3 & 7 & 12 & -5 \\
22 & 13 & 14 & -1 \\
24 & 16 & 21 & -5 \\
\hline
\end{tabular}

Overall, participants were dissatisfied with arguments in the think-aloud text that opposed the compulsory teaching of te reo Māori in New Zealand and disparaged the unique position and status of both tīkanga Māori and te reo Māori in New Zealand.

These findings further complement Edwards and Smith (1996) disconfirmation model. Participants in this group subjected belief-incompatible arguments to heavy scrutiny, which differs to the strategy used by participants who gave more supportive 
arguments for belief-compatible arguments (Corner et al., 2012). They had judged belief-incompatible arguments weaker than pre-existing beliefs or belief-compatible arguments. They have then generated more refutational comments for beliefincompatible arguments (Edwards \& Smith, 1996).

\subsection{Post-reading belief-change and belief-maintenance}

Three groups were identified post reading: 1) belief maintenance, 2) beliefstrengthening and 3) strong-supporters. Six of the 23 participants of this study indicated feeling a strengthening of their pre-existing beliefs. Seventeen of the 23 participants although not experiencing belief-change were either classed as supporters $(n=7)$ or strong-supporters $(\mathrm{n}=10)$ of compulsory te reo Māori in New Zealand schools.

All of the 23 participants in the current research although at different levels of support for compulsory te reo Māori, were all supportive of the controversial issue. This presents two different levels of issues; first, a group opposing compulsory te reo Māori and the themes they might cover and second, no baseline data (should be gathered before commencing in the post-graduate teaching diploma) to compare and contrast beliefs and attitudes.

Those who indicated experienced belief-change acknowledged their pre-existing belief strengthening towards the compulsory teaching of te reo Māori in response to the first question of the interview. Those participants who maintained pre-existing beliefs seemed justified to discredit belief-incompatible arguments, and at the same time the supporting arguments did not encourage further support for compulsory te reo Māori.

These findings are consistent with belief polarisation (Edwards \& Smith, 1996; Lord et al., 1979) and a couple of Chinn and Brewer (1998) findings on responses to anomalous data (rejection and reinterpretation of argument).

A polarisation of beliefs can occur following contact with both belief-compatible and belief-incompatible arguments (Edwards \& Smith, 1996; Lord et al., 1979). Belief polarisation can occur from a need to revise existing beliefs as a result of interacting with belief-incompatible arguments (Tillema, 2000).

Chinn and Brewer (1998) article may help enlighten those participants who maintained beliefs. Participants whose beliefs did not change could have experienced one of the following responses. First, Chinn and Brewer (1998) define 'rejection' as denying the validity of the belief-incompatible data, however further refutational arguments are provided in order to undermine the evidence. And lastly, reinterpretation 
of argument' Chinn and Brewer (1998) is defined as a process engaged in by participants who modify and explain the data without changing existing beliefs. The responses provided by Chinn and Brewer (1998) result in belief-maintenance or no belief-change and could explain the reasons for participants not experiencing belief-change.

The qualitative data analysis further supports previous research on biased assimilation, and belief polarisation (Corner et al., 2012; Edwards \& Smith, 1996; Greitemeyer et al., 2009; Lord et al., 1979; Plous, 1991).

\subsection{Limitations of the current study}

The current research takes into consideration a range of limitations that have been considered throughout analysing both quantitative and qualitative data, producing themes and results. These limitations have not greatly impacted the results provided by this study. It does however provide suggestions as to how this study could be improved in order to make stronger claims within this field of study. It also has provided suggestions for further study. There were four main limitations of this study.

The first would be the low sample size $(n=23)$. It is interesting to note that the female, male ratio ( 17 female, 6 male) of participants in the current study reflect the general nature of female and male teachers in New Zealand (73\% female, 27\% male) (Ministry of Education, 2013b). The pre-service teacher participants were concluding their year of study at the university and this makes conclusions drawn from this study tentative. Future research should seek to replicate the findings using a larger sample size.

Second, there was no baseline data for comparison of pre-study and post-study belief-change and the effect a year in postgraduate teaching diploma can have challenging negative bias and attitudes towards teaching the Māori language and culture within the New Zealand English-medium education system. There was also no comparable data by those who oppose compulsory teaching of te reo Māori in New Zealand schools and the effect the think-aloud task while reading a balanced text can have on belief-change. Further research should also attempt to gather data from this group of pre-service teachers at the beginning of the year to account for the difference between pre-study and post-study, and those who oppose the controversial topic to assess the effect the think-aloud task has on belief-change.

The third, analysis of qualitative data revealed six participants believed to experience belief-change by reading the think-aloud text. However, it was difficult to identify their specific reasoning for this belief-change. For example in response to 
question one of the interview participant \#3 responded: 'Um. No, not particularly-, I mean I did, I did see obviously the very specific arguments and see how the two sides of them work but to me I've always felt like, the real, $\mathrm{mmm}$, debate, or the real reason why it should be compulsory sort of wasn't touched on. That was sort of my mind set when I came in'. This suggests that assessing belief-change only through think-alouds and interviews may not be enough to develop a complete picture of belief-change and reasoning for these changes.

\subsubsection{Implications and Recommendations}

The results of this study are aimed at numerous stakeholders: namely teacher training institutions, lecturers and tutors within teacher education, pre-service teaching students, program developers. Understanding the power of pre-existing beliefs may assist program developers in developing range of teaching strategies that influence the approach to culturally responsive education. In particular Māori enjoying educational success as Māori, as stipulated by the governments' educational goals in the Ka Hikitia Māori educational strategy (Ministry of Education, 2013a). Specifically, the implications of this study include:

1. All participants within this group of pre-service teachers accept that tīkanga Māori and te reo Māori have a unique place within the New Zealand education system.

2. Pre-service teachers benefit from the personal experiences they have both within New Zealand amongst Māori and the Māori world, and also on an international scale.

3. The institutional challenge for pre-service teacher education is restructuring the teaching program to allow for more culturally experiential learning.

4. Measuring and encouraging belief change via text alone exercises (such as written assignments and essays) may not be effective in order to change preexisting beliefs and attitudes towards controversial issues. Participant self reports (as gained through think-aloud exercises and interviewing) can be an unreliable source of data on their own (Meyer, 2011). More research needs to be done to investigate teacher training programs that enable participants to critically engage with their own existing beliefs and values, as well as processes that enable belief change and the development of culturally 
responsive and inclusive pedagogies.

This study provides a useful insight into pre-service teacher attitudes and beliefs on a controversial issue in education here in Āotearoa, New Zealand. The main educational implication of the present study is that teacher training institutions reevaluate the effectiveness of relying heavily on text to inform belief-change regarding a controversial issue such as te reo Māori me ōna tikanga (Māori language and customs). 


\section{REFERNCES:}

Bishop, R., \& Berryman, M. (2007). Culture speaks: Cultural relationships \& classroom learning. Wellington: Huia publishers.

Bishop, R., Berrymann, M., Cavanagh, T., \& Teddy, L. (2009). Te kotahitanga: Addressing educational disparities facing Māori students in New Zealand. . Teaching and Teacher Education, 1-9. doi: 0.1016/j.tate.2009.01.009

Burnard, P. (1991). A method of analysing interview transcripts in qualitative research. Nurse Education Today, 11(6), 461-466. doi: 10.1016/0260-6917(91)90009-Y

Chinn, C. A., \& Brewer, W. F. (1998). An empirical test of a taxonomy of responses to anomalous data in science. Journal of Research in Science Teaching, 35(6), 623654. doi: 10.1002/(SICI)1098-2736(199808)35:6<623::AID-TEA3>3.0.CO;2-O

Corner, A., Whitmarsh, L., \& Xenias, D. (2012). Uncertainty, sceptisim and attitudes towards climate change: Biased assimilation and attitude polarisation. Climatic Change, 114(3-4), 463-478. doi: 10.1007/s10584-012-0424-6

Creswell, J. W., \& Clark, V. L. P. (2007). Designing and conducting mixed methods research. Thousand Oaks, CA: Sage Publications.

Edwards, K., \& Smith, E. E. (1996). A disconfirmation bias in the evaluation of arguments. Journal of Personality and Social Psychology, 71(1), 5-24. doi: $10.1037 / 0022-3514.71 .1 .5$

Evans, A. (2010). Top school makes te reo compulsory. The New Zealand Herald. Retrieved from http://www.nzherald.co.nz/nz/news/article.cfm?c id=1\&objectid=10685323

Gill, A. M., \& Nonnecke, B. (2012). Think aloud: Effects and validity. Paper presented at the Proceedings of the 30th ACM international conference on Design of communication.

Greitemeyer, T., Fischer, P., Frey, D., \& Schulz-Hardt, S. (2009). Biased assimilation: The role of source position. European Journal of Social Psychology, 39(1), 2239. doi: $10.1002 /$ ejsp.497

Hale, K., Krauss, M., Watahomigie, L. J., Yamamoto, A. Y., Craig, C., Jeanne, L. M., \& England, N. C. (1992). Endangered languages. Language, 68(1), 1-42.

Human Rights Commission. (2008-2013). New Zealands official languages. Retrieved from http://www.hrc.co.nz/enquiries-and-complaints-guide/faqs/new-zealandsofficial-languages 
Humphreys, J. (2012). Groser's support for te reo impractical, says Peters. 3 News.

Retrieved from http://www.3news.co.nz/Grosers-support-for-te-reo-impracticalsays-Peters/tabid/1607/articleID/252207/Default.aspx

Igo, L. B., Bruning, R. A., \& Riccomini, P. J. (2009). Should middle school students with learning problems copy and paste notes from the internet? Mixed-methods evidence of study barriers. Research in Middle Level Education Online, 33(2), 110 .

Ka'ai-Mahuta, R. (2011). The impact of colonisation on te reo Māori: A critical review of the state education system. Te Kaharoa, 4(1), 195-225.

Kane, R. G., Burke, P., Cullen, J., Davey, R., Jordan, B., McCurchy-Pilkington, C., . . . Godin-McKerras, L. (2005). Initial teacher education policy and practice (pp. 301): Massey University.

Klaczynski, P. A., \& Gordon, D. H. (1996). Self-serving influences on adolescents' evaluations of belief-relevant evidence. Journal of Experimental Child Psychology, 62(3), 317-339. doi: 0022-0965/96

Kucan, L., \& Beck, I. L. (1997). Thinking aloud and reading comprehension research: Inquiry, instruction, and social interaction. Review of Educational Research, 67(3), 271-299. doi: 10.3102/00346543067003271

Kunda, Z. (1990). The case for motivated reasoning. Psychological reasoning, 108(3), 480-498. doi: 0033-2909/90

Levy, D. (2011). Clash over te reo in schools. Retrieved from http://www.stuff.co.nz/national/politics/policies/5941152/Clash-over-Te-Reo-in$\underline{\text { schools }}$

Lord, C. G., Ross, L., \& Lepper, M. R. (1979). Biased assimilation and attitude polarization: The effects of prior theories on subsequently considered evidence. Journal of Personality and Social Psychology, 37(11), 2098-2109. doi: 10.1037/0022-3514.37.11.2098

McCrudden, M. T. (2012). Readers' use of online discrepancy resolution strategies. Discourse Processes, 49(2), 107-136. doi: 10.1080/0163853X.2011.647618

McCrudden, M. T., Magliano, J. P., \& Schraw, G. (2010). Exploring how relevance instructions affect personal reading intentions, reading goals and text processing: A mixed method study. Contemporary Educational Psychology, 35(4), 229-241. doi: 10.1016/j.cedpsych.2009.12.001 
McFalls, E. L., \& Cobb-Roberts, D. (2001). Reducing resistance to diversity through cognitive dissonance instruction: Implications for teacher education. Journal of Teacher Education, 52(2), 164-172. doi: 10.1177/0022487101052002007

Meyer, L. H. (2011). Evaluating the effectiveness and impact of teacher professional development. In C. E. Sleeter (Ed.), Professional development for culturally responsive and relationship-based pedagogy (pp. 69-90). New York: Peter Lang Pub.

Ministry of Education. (2007). The New Zealand curriculum. Wellington: Learning Media.

Ministry of Education. (2013a). The Māori education strategy: Ka hikitia - Accelerating success 2013 -2017. Retrieved from http://www.minedu.govt.nz/theMinistry/PolicyAndStrategy/KaHikitia/StrategyO verview.aspx

Ministry of Education. (2013b). Teaching staff. Education Counts Publications. Retrieved from http://www.educationcounts.govt.nz/statistics/schooling/teaching_staff Murphy, P. K., \& Mason, L. (2006). Changing knowledge and beliefs. In P. A. Alexander \& P. H. Winnie (Eds.), Handbook of educational psychology (pp. 305324). Mahwah, NJ, USA: Lawrence Erlbaum Associates Publishers.

Nir, L. (2011). Motivated reasoning and public opinion perception. Public Opinion Quarterly, 75(3), 504-532. doi: 10.1093/poq/nfq076

Penetito, W. (2010). What's Māori about Māori education? Wellington: Victoria University Press.

Plous, S. (1991). Biases in the assimilation of technological breakdowns: Do accidents make us safer? Journal of Applied Social Psychology, 21(13), 1058-1082. doi: 10.1111/j.1559-1816.1991.tb00459.x

Skyhawk, S. (2012). Why should we keep tribal languages alive? Retrieved from http://indiancountrytodaymedianetwork.com/article/why-should-we-keep-triballanguages-alive $\% 3 \mathrm{~F}-99182$

Taber, C. S., \& Lodge, M. (2012). Motivated skepticism in the evaluation of political beliefs (2006). American Journal of Political Science, 50(3), 755-769. doi: 10.1111/j.1540-5907.2006.00214.x 
Tillema, H. H. (2000). Belief change towards self-directed learning in student teachers: Immersion in practice or reflection on action. Teaching and Teacher Education, 16(5-6), 575-591. doi: 10.1016/S0742-051X(00)00016-0

Tippett, C. D. (2010). Refutation text in science education: A review of two decades of research. International Journal of Science and Mathematics Education, 8(6), 951970. doi: 10.1007/s10763-010-9203-x

Turner, D. W. I. (2010). Qualitative interview design: A practical guide for novice investigators. The Qualitative Report, 15(3), 754-760.

Waitangi Tribunal. (2010). Te Reo Māori WAI 262 report (pp. 126). Wellington, New Zealand.

Wiley, J. (2005). A fair and balanced look at the news: What affects memory for controversial arguments? Journal of Memory and Language, 53(1), 95-109. doi: 10.1016/j.jml.2005.02.001 


\section{Āpitihanga - Appendix A}

"We are interested in investigating how people develop their opinions and what people think of information that they agree and disagree with. You will be presented a short passage that includes ideas in support of and in opposition whether te reo Maori should be compulsory in New Zealand primary and secondary schools. In order to understand how people develop their opinions, we need you to think out loud while you are reading. We would like you to say everything you are thinking out loud while you read the text. That is, please say out loud any thoughts that come to mind at any point during the reading. But in particular, whenever you see three stars $(* * *)$ after a sentence, we need you to comment out loud. Before we begin, you will have the opportunity to practice with a shorter passage." 


\section{Āpitihanga - Appendix B}

Practice text

1. In recent years there has been a great deal of debate about whether the drinking age in New Zealand should be raised from 18 years of age to 20 years of age.

2. There are people with opinions on both sides of the issue. Some people support an increase in the drinking age to 20, whereas others oppose an increase in the drinking age from 18 to $20 . * * *$

3. Those who are support an increase in the drinking age to 20 argue that excessive and binge drinking cost the health system millions of dollars each year.***

4. For example, Andrew Dickenson, a member of the Canterbury District Health Board, says, "We know the harm that alcohol can do," he said.

5. "Crime goes up, there's more sexual assault, domestic violence, unwanted pregnancies, and I support this position statement 100 per cent."

6. Thus, an increase in age will reduce many health-related injuries and medical costs. $* * *$

7. Those who oppose an increase in the drinking age to 20 argue that it is wrong to deny people the right to buy alcohol at age 18 when they are given many other responsibilities at age $18 . * * *$

8. For example, National MP Nikki Kaye says, "If someone can be elected to Parliament, get married, or join the army, then they should be able to buy a bottle of wine."

9. Thus, an age increase should be opposed because it is inconsistent with other laws. $* * *$ 


\section{Āpitihanga - Appendix C}

\section{Should te reo Māori be compulsory in New Zealand schools?}

Te Reo Māori is the native language of the Māori, who are the indigenous peoples of New Zealand. Te reo Māori me ōna tīkanga refers to Māori language and customs. Recently, there has been a great deal of debate about whether te reo Māori should be compulsory in New Zealand primary and secondary schools. There are people on both sides of the issue. Some people support compulsory te reo Māori in schools, whereas others oppose this idea.

This text presents some arguments on this topic. ${ }^{* * *}$

Some who oppose compulsory te reo Māori in schools argue that it is more useful to teach other languages, such as Chinese.*** For example, New Zealand's trade with China has increased dramatically in the past 10 years, and additional trade agreements are in place to ensure that there will be more trade in the future. Thus, learning Chinese languages and customs, for example, is more useful than learning te reo Māori because it is more economically-beneficial to learn about other languages and cultures. ${ }^{* * *}$

Some who support compulsory te reo Māori in schools argue that familiarity with other cultures can enhance a person's ability to work with people from different cultures, which can increase their employment opportunities. ${ }^{* * *}$ For instance, Tim Grosser, New Zealand Trade Minister suggests workers who are highly effective in international business have learnt to work in new cultural spaces. The Māori language and culture is an accessible cultural space in New Zealand where people can learn about another culture and increase their effectiveness in international business settings, both at home and abroad. Thus, te reo Māori should be compulsory in schools because it can increase a person's employment opportunities. ${ }^{* * *}$

Some who oppose compulsory te reo Māori in schools argue that it diverts time and energy away from more useful school subjects. ${ }^{* *}$ For example, a parent who recently commented on New Zealand's channel 3 news website stated, "Our schools need to be preparing our kids for a competitive world with subjects that allow them to use what they learn. Maori is a dead language in the modern world and I'd rather have my child learn useful things like proper English, maths, economics, science, computer studies, life skills." Therefore, compulsory te reo Māori should be opposed because schools should be teaching more useful subjects. ${ }^{* * *}$

Some who support compulsory te reo in schools argue that learning a second language improves "mental agility".*** For example, Dr Paula Rubio Fernandez, a researcher at University College London says, "Multi-linguists are forced to select the appropriate language for every situation and this helps improve the brain's cognitive functioning for things like problem solving, verbal reasoning, and multi-tasking." Further, she says, "For people who have to switch between languages, it helps you finetune your attention." Thus, compulsory te reo Māori should be supported because it can boost mental functioning.*** 
Some who oppose compulsory te reo Māori in schools argue that English is already an effective language in New Zealand and learning te reo Māori is unnecessary.*** For example, an Auckland man wrote the following on a New Zealand news website: “My country's language is English. It is spoken and understood by the vast majority of New Zealand citizens. A language exists to enable effective communication between people. The recent attempts to revive Māori are a foolish exercise; it should have been allowed to quietly continue to fade away." Thus, compulsory te reo Māori should be opposed because it is unnecessary; English is spoken and understood by the majority of New Zealanders.***

Some who support compulsory te reo in schools argue that the use of te reo Māori in everyday New Zealand creates value and respect for the Māori language and culture.*** For example, Dr John Macalister, the head of Victoria University's School of Linguistics says, "There are some people who would say it is tokenistic. It is much more than that. The very fact that you are choosing to use someone else's language is a sign of respect and of valuing the other person." Thus, compulsory te reo should be supported because it helps build value and respect for Māori language and culture.***

Some who oppose compulsory te reo Māori in schools argue that the majority of New Zealand students are not Māori and shouldn't be required to learn it.*** For instance, a couple from Gisborne objected to their daughter being taught te reo Māori by saying, "We are not of Māori culture, our daughter is not of Māori culture. So, we don't understand why our child should have to learn it". Thus, compulsory te reo Māori in schools should be opposed because the majority of New Zealand students are not Māori.***

Some who support compulsory te reo Māori in schools believe that there are social benefits to learning te reo Māori and customs. ${ }^{* * *}$ There are many opportunities for non-Māori to be socially-involved with Māori at work, at school, and at social and family gatherings (for example, funerals, birthday parties and weddings). Becoming knowledgeable about Māori customs and practices will ensure confidence, competence and access to these activities. Thus, compulsory te reo should be supported because it provides social benefits. ${ }^{* * *}$

Some who oppose compulsory te reo Māori in schools argue that New Zealand is a multicultural country and compulsory te reo Māori privileges Māori culture over other cultures. ${ }^{* * *}$ For instance, Don Brash a previous leader of New Zealand's National political party said, "We are one country with many peoples, not simply a society of Pākehā and Māori where the minority has a birthright to the upper hand." That is, focusing on Māori things creates a racially divided New Zealand, and privileges Māori above others. Thus, compulsory te reo Māori should be opposed because it privileges Māori culture within a multicultural country.***

Some who support compulsory te reo in schools argue that te reo Māori is an endangered language and that making it compulsory is one way to ensure its survival and revitalization.*** Much like the kiwi bird, the survival of te reo Māori is threatened. Today, few New Zealanders use te reo Māori as a language of everyday communication. Thus, compulsory te reo Māori should be supported because it is one way to ensure its survival and revitalization. ${ }^{* * *}$ 


\section{Āpitihanga - Appendix D}

\section{$\underline{\text { Interview Questions }}$}

1. Now that you have read various views about making te reo Māori compulsory, has your attitude towards this topic changed? (Let person respond, then ask the following probe: "Please explain.")

2. (Will ask this one multiple times based on your notes taken during the thinkaloud) After reading Sentence X you said, “* *". Do you remember what you were thinking when you read Sentence $X$ ? (If yes, ask him/her to explain.)

3. Can you describe your general reactions to reading sentences $\mathrm{A}, \mathrm{B}$, and $\mathrm{C}$ ? (support sentences)

4. Can you describe your general reactions to reading sentences X, Y, and Z? (opposition sentences)

5. What types of information did you find more relevant while you read?

6. What types of information did you find less relevant while you read?

7. Do you have any other general comments that you'd like to make?

Thank the person for participating; debrief and dismiss 


\section{Āpitihanga - Appendix E}

\begin{tabular}{|c|c|c|}
\hline \multicolumn{3}{|c|}{ Coding Scheme for Think-aloud Comments } \\
\hline Statement Type & Definition & Example \\
\hline $\begin{array}{l}\text { Evaluation: Agree } \\
\text { (Simple) }\end{array}$ & Agree with the current sentence & "I'd agree with that" \\
\hline $\begin{array}{l}\text { Evaluation: Disagree } \\
\text { (Simple) }\end{array}$ & Disagree with the current sentence. & "Well, no, not really" \\
\hline $\begin{array}{l}\text { Evaluation: Agree } \\
\text { (Elaboration) }\end{array}$ & $\begin{array}{l}\text { Using background knowledge to argue in support of } \\
\text { an argument in the current sentence. }\end{array}$ & $\begin{array}{l}\text { "Yea I agree with that. I think children just benefit by having parents that just really love } \\
\text { them. Doesn't really matter if it's one or two or if they're recognized by law, they just } \\
\text { need two parents. Well they need parents or a parent really." }\end{array}$ \\
\hline $\begin{array}{l}\text { Evaluation: Disagree } \\
\text { (Elaboration) }\end{array}$ & $\begin{array}{l}\text { Use background knowledge to counter-argue/rebut } \\
\text { the argument in the current sentence. }\end{array}$ & $\begin{array}{l}\text { "Well, no, I don't agree with that. I think that if two people love each other and they can } \\
\text { make a home for a child then that child who didn't have a home before will be very } \\
\text { happy." }\end{array}$ \\
\hline $\begin{array}{l}\text { Positive Affective } \\
\text { Response }\end{array}$ & $\begin{array}{l}\text { Positive emotional comment regarding the current } \\
\text { sentence }\end{array}$ & "Cool" \\
\hline $\begin{array}{l}\text { Negative Affective } \\
\text { Response }\end{array}$ & $\begin{array}{l}\text { Negative emotional comment regarding the current } \\
\text { sentence }\end{array}$ &  \\
\hline Uncertainty & $\begin{array}{l}\text { Comment that indicates doubt about the validity of } \\
\text { the current sentence due to a lack of background } \\
\text { knowledge. }\end{array}$ & "I don't know what the 'nature of marriage' is?" \\
\hline Attitude Bolstering & $\begin{array}{l}\text { Bringing facts that support one's position to mind } \\
\text { without directly refuting the contradictory } \\
\text { information. } \\
\text { (Bait and switch) }\end{array}$ & $\begin{array}{l}\text { "Well I see it as more of a special treatment for minority, it's no more than } 2 \% \text { of the New } \\
\text { Zealand society... and you're changing things to... bend over backwards to... support this } \\
\text { minority group. No more than } 2 \% \text {, it's special law; it's going to lead to more inequality in } \\
\text { a democratic society where apparently everyone is equal." }\end{array}$ \\
\hline Source Derogation & $\begin{array}{l}\text { Dismissing the expertise or trustworthiness of the } \\
\text { source. }\end{array}$ & $\begin{array}{l}\text { "National Civic Council sounds really important but is often front names that sound really } \\
\text { important and big. But I have seen so many of these front names but this Peter Westmore } \\
\text { could be the only member of this civic council. So... but it sounds more authoritative than } \\
\text { Peter Westmore, a**hole from Blenheim, Peter Westmore, President of National Civic } \\
\text { Council. It gives them some kind of pseudo authority through having a title." }\end{array}$ \\
\hline Cognitive Conflict & Attempt to reconcile text info with existing beliefs. & $\begin{array}{l}\text { "Ah I see, so that would be the main idea. Which I said I have reservations about but most } \\
\text { of these are because my mum believed, as a teacher, has met some parents who split and } \\
\text { then went into a homosexual relationship and she said the child seemed rather } \mathrm{f}^{* * *} \text { ed up, } \\
\text { if you will, as a result. But in saying that, I have gay friends myself and feel that they } \\
\text { would make good parents and if children need to be adopted and there's a need for it then } \\
\text { definitely gay parents better than no parents at all." }\end{array}$ \\
\hline $\begin{array}{l}\text { Monitoring } \\
\text { comprehension }\end{array}$ & $\begin{array}{l}\text { Reflecting on own understanding, or confirming an } \\
\text { inference made earlier in the text }\end{array}$ & "I have to read that again. I'm a bit confused by that sentence." \\
\hline
\end{tabular}




\section{Āpitihanga - Appendix F}

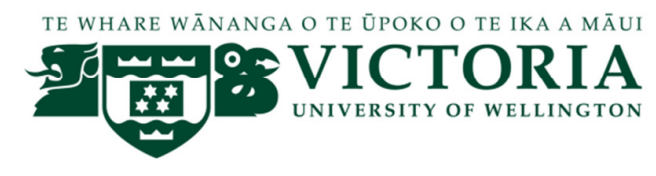

Project Title: Beliefs and knowledge in multiple-source comprehension Ethics Application \#: 19389

My name is Matt McCrudden and I am an Associate Professor in the School of Educational Psychology and Pedagogy at Victoria University of Wellington in New Zealand. The purpose of this study is to examine how students learn about a topic from people who have different perspectives. It is hoped that this study will help educators understand how people develop their thinking when they read.

Participation: If you choose to participate in this study, you will complete a questionnaire on your beliefs about a controversial topic. Then you will read information from different perspectives on this topic. You will think-aloud (i.e., say your thoughts outloud) as you read. After reading, you will complete the questionnaire again and you will write a short essay in which you will be asked to justify your stance on the topic. You will be invited to participate in an interview. If you choose to participate in the interview, you will be asked to describe the strategies you used while you read and to explain why you decided to include the information that you provided in your essay. The study will take approximately 1 hour to complete.

You are not required to participate in this study. Your decision about whether you want to participate in this project will not affect your present or future relationship with Victoria University of Wellington. If you decide to participate, you have the right to withdraw your consent at any time and discontinue your participation. Your decision to discontinue participation will not affect your present or future relationship with Victoria University of Wellington.

Confidentiality: Any information that can be identified with you will remain confidential. The results of this project will be presented in written and oral reports, but your name will not be used in any written or oral reports. I will not provide any personal information that could be used to identify you in any reports.

Ethics: This research has been assessed and approved by Victoria University Faculty of Education Ethics Committee. If at any time you have any questions or concerns about your treatment as a research participant in this study, contact Dr Allison Kirkman, who is current Chair of the university ethics committee (telephone: +64 4463 5676).

Data Storage and Deletion: Once the study is finished the information collected in the study will be entered into a computer belonging to the investigators for this project. These data will not be identifiable in any way. The data will be stored in a locked office in the Faculty of Education building for 3 years after the completion of the study and will then be destroyed. 
Reporting/Dissemination: The results of this study will be submitted for publication in research journals and may be presented at a conference. If you are interested in receiving a copy of the final report from this study then please contact Dr McCrudden.

If you have any questions about the study now or at any time in the future, please feel free to contact the primary researcher using the following contact information: Dr Matt McCrudden, Associate Professor, School of Educational Psychology and Pedagogy, Faculty of Education, Victoria University of Wellington, PO Box 17-310, Karori, Wellington, NZ, +64 4463 5179, matt.mccrudden@vuw.ac.nz

Sincerely,

Matt McCrudden 


\section{Āpitihanga - Appendix G}

\section{Participant consent form}

Project Title: Beliefs and knowledge in multiple-source comprehension (study \#2) Ethics Application \#: 19389

I agree to take part in the above research. I have had the project explained to me and I have had a chance to ask questions. I understand that agreeing to this means that I will be willing to do the following: (please tick circle)

- I agree to take part in this research project and to allow my answers to be collected and analysed.

- I understand that I don't have to take part in the research and that I may withdraw from this project without having to give a reason.

- I understand that any information I provide will be kept confidential to the researcher and that I will not be identified in the research or any reports on the project. $\circ \quad$ I understand that any information from this project will be destroyed after three years.

- I understand that I will be asked to complete a questionnaire on my beliefs and knowledge about a controversial topic before and after reading.

$\circ \quad$ I understand that I will be asked to verbalize outloud what I am thinking as I read.

$\circ \quad$ I understand that I will be asked to provide a written justification of my stance on a controversial topic.

$\circ \quad$ I understand that I will participate in an interview to describe the strategies I used while I read and to explain why I decided to include the information that I provided in my written justification.

Name:

Date:

Signature: 


\section{GLOSSARY}

Āpitihanga - Appendix

Ngā mihi - Acknowledgments

Pākehā - New Zealander of European descent

Te reo Māori - The Māori language

Te reo Māori me ōna tīkanga - Māori language and customs

Wāhanga - Section

Whānau - family 